\title{
SANTANDER: REDISTRIBUIDOR EUROAMERICANO DE MERCANCÍAS (1766-1785)
}

por

ISABEL MIGUEL LÓPEZ

Instituto de Historia Simancas. Valladolid

RESUMEN: La vinculación inicial del puerto de Santander con el Consulado de Burgos generó un conjunto de documentación, hasta abora no utilizada, que ha sido empleada en este estudio, para analizar el movimiento comercial desarrollado en torno al puerto cántabro, entre 1766 y 1785. Periodo que transcurre entre su babilitación para el comercio con Barlovento y la creación de su propio Consulado y que constituye la etapa previa a su apogeo comercial, durante la cual se definen las pautas de su trayectoria posterior que otorgan la peculiaridad a este puerto. La información disponible ba posibilitado el acercamiento a la composición de los flujos comerciales, a quiénes intervinieron en ellos y a las directrices de los intercambios, proporcionando la imagen de Santander como un puerto redistribuidor de productos externos, que vincula el oeste de Europa, la mitad norte de España y América, configurando un espacio económico en el que comienzan a tejerse redes comerciales con vectores urbanos dominantes. Este proceso acaece cuando se asiste a la modificación de las posiciones de los puertos cantábricos, de la que Santander sale beneficiado, como expresa su crecimiento favorecido por el impulso americano.

Palabras ClaVE: Comercio. Redes comerciales. Santander. Siglo XVIII. Historia Económica.

ABSTRACT: This article analyses the commercial activity generated by the port of Santander between 1766 and 1785, using bitherto unstudied documentation relating to the linking of the port with to the Consulado de Burgos at that time. During that period the port was only qualified for trading Windward and did not yet have its own Consulate; it constitutes a stage previous to its commercial apogee. The documentation analysed shows the nature of the commercial flows, the participants in this trade, and the guidelines used in this initial period. An image of Santander emerges as port specialising in imports, linking Western Europe, Northern Spain and the Americas, configuring an economic space in which commercial networks with dominant urban vectors are starting to be established. This process occurs at a time when the relative positions of the Cantabrian ports chainge, to the benefit of Santander, as is reflected in the growth favoured by its trade with the Americas. 
KeY WORDS: Trade. Commercial networks. Santander. Cantabria. Eighteenth Century. Economic History.

\section{INTRODUCCIÓN}

La progresiva expansión del puerto de Santander a lo largo del siglo XVIII constituye un proceso que tiene como expresiones la concesión del título de ciudad en 1755, la consolidación de su función de puerto de Castilla con la mayor frecuencia de utilización del camino de Reinosa, su paulatina vinculación con América tras la habilitación en 1765 , confirmada en $1778^{1}$, así como el incremento demográfico de la ciudad ${ }^{2}$ y el anhelo por desvincularse del Consulado de Burgos, lo que se logra tras la creación del propio en 1785.

Precisamente, la relación administrativa con la institución burgalesa incluía, según la Real Cédula de 15 de julio de 1766 que restablecía el viejo Consulado de la ciudad castellana, la «contribución a aquel de un cuartillo por ciento de los géneros que se aduanasen en Santander, a cambio de poner y mantener un repuesto de cables y anclas en su puerto para socorrer a las embarcaciones que entrasen y saliesen y precaver naufragios y averías» ${ }^{3}$. Este procedimiento impositivo generó una documentación de miles de registros que constituyen una fuente de información susceptible de ser empleada para el análisis del comercio durante el periodo que transcurre entre 1766 y 1785 y que es la utilizada en este estudio ${ }^{4}$. La razón es que proporciona información diaria, a lo largo de los doce meses del año, relativa a los productos y su cantidad, al transportista y su vecindad y habitualmente al destino y ciertos destinatarios, además del gravamen fiscal, si procede ${ }^{5}$. Estos datos ofrecen, en consecuencia, la posibilidad de acercarse, entre otros, a la composición de los flujos comerciales generados en torno a Santander, a la presencia de los artículos extranjeros en las transacciones, a su distribución por el territorio peninsular, América y Europa. Es decir, aspectos que aportan una imagen más compleja de la econo-

I Martínez VARA, Tomás: Santander de villa a ciudad. Un siglo de esplendor y crisis, Santander, 1983. Zabala, Aingeru: «La distribución de la actividad comercial en el Cantábrico en torno a los decretos de Libre Comercio» en Mercado y desarrollo económico en la España Contemporánea, Madrid, 1986, pp. 41-67. MigueL, Isabel: El comercio bispanoamericano a través de Gijón, Santander y Pasajes, Valladolid, 1992.

2 Santander tenía 557 vecinos en 1752 que se elevaron a 1217 en 1787.

3 MOLAS, Pedro: «La restauración del Consulado de Burgos en el siglo XVIII» en Actas del Congreso de Historia de Burgos, Burgos, 1985, pp. 429-440

1 Archivo de la Diputación de Burgos. Consulados, Libros R-76, R-78, R-79, R-80, R-81, R82, R-83, R-84, R-86, R-94. Los datos de 1766 se refieren sólo a 2 meses, noviembre y diciembre, mientras se incorporan todos los meses de los años 1767, 1770, 1773, 1774, 1775, 1777, 1780, $1782,1784,1785$ que son los conservados en este fondo documental.

5 Los gravámenes incluidos se refieren al cuartillo por ciento $(0,25 \%)$ para el Consulado de Burgos y al impuesto para Su Majestad del $15 \%$.

Hispania, LXIV/2, núm. 217 (2004) 601-636 
mía del Antiguo Régimen, del modelo de consumo de la época y propicia la configuración del ámbito de influencia comercial del puerto cántabro, su articulación con otros circuitos económicos a través de las redes de transporte y de comercio, sobre todo del interior hispano, en el periodo previo al esplendor santanderino, el de su gestación, el menos estudiado, lo que confiere mayor valor a la documentación.

Sin embargo, la fuente histórica empleada ofrece algunas limitaciones derivadas del carácter fiscal de la misma, pues, en la práctica, la recaudación se «arregla a los Aranceles de esta Aduana» y, según estos, no son todos los productos los que tributan, ya que los de origen hispanoamericano no están sometidos a recaudación desde 1778, así como tampoco los que se destinan a Ordenes Religiosas o a los Reales Hospitales, ni productos del Reino como el trigo, el aceite, los cueros de la Montaña, ni los destinados a la Franquicia santanderina, ni ciertas partidas declaradas libres por Real Decreto. Ello explica que, si bien puede disponerse de los datos absolutos de cada producto, no sea posible establecer para todo el periodo, a partir de la recaudación, el porcentaje que cada grupo de mercancías significa en el conjunto ${ }^{6}$.

En cualquier caso, este acervo documental, por su riqueza informativa, abre la posibilidad de conocer el detalle de una determinada realidad, lo que no siempre es posible, aunque sea deseable, en la investigación histórica. Así pues, con las cautelas requeridas se abordan algunos aspectos planteados anteriormente.

\section{I. ¿QUÉ, CUÁNTO Y A DÓNDE?}

El análisis de los diversos artículos comercializados ha permitido calibrar su posición y ese rango de importancia percibido, que se expone seguidamente, diseña la estructura de las remesas comerciales, si bien su cuantificación absoluta ha requerido tener que superar el inconveniente de la multiplicidad de medidas empleadas en la documentación.

\section{I.1. Protagonismo alimentario}

De la multitud de productos con los que se comercia, los alimentos representan la partida fundamental, según las referencias a ellos dedicadas, puesto que superarían el sesenta por ciento del total, si bien ya sólo el bacalao, azúcar

6 Únicamente para el año 1770 se aporta también el valor de las mercancías y esta variable podría emplearse para calcular las proporciones. En consecuencia sólo restaría para una mera aproximación, considerar el número de veces que se anota un determinado tipo de productos respecto al global de registros de ese año, lo que aportaría un dato cifrado que añadir a la percepción valorativa de quien lo estudia. 
y cacao, es decir comestibles de origen foráneo, constituían, por término medio, el cincuenta y cinco por ciento de los registros a lo largo de estos años.

Entre estos, el bacalao ofrece una presencia dominante, respondiendo a un consumo que en España era secular ${ }^{7}$, sobre todo en Cuaresma, hasta el punto de que sólo es contrarrestado en las cargazones por el azúcar en los años ochen$\mathrm{ta}$, cuando le iguala e incluso le supera. El origen del renombrado pescado fue cambiando a lo largo del siglo ante el empuje noruego en las capturas ${ }^{8}$ y entre las diversas calidades se encuentran las denominadas «lenguas» que era la superior, originaria de Terranova9 ${ }^{9}$. La distribución desde Santander durante los años analizados presenta, entre 1770 y 1777 , un comportamiento en el que desde un comienzo débil, se duplican las cantidades, destacando 1775 que rebasa las 95.000 arrobas, es decir más de 1000 toneladas. Posteriormente, se acusan los efectos de la Guerra de Independencia de las colonias británicas de América del Norte, especialmente perceptibles en 1780 y 1782, cuando el tráfico marítimo en el Atlántico se ve dificultado por el conflicto, asistiendo a la recuperación desde 1784 que alcanza valores similares a los de 1767 (Gráfico I).

GRÁFICO I: Bacalao distribuido a través de Santander

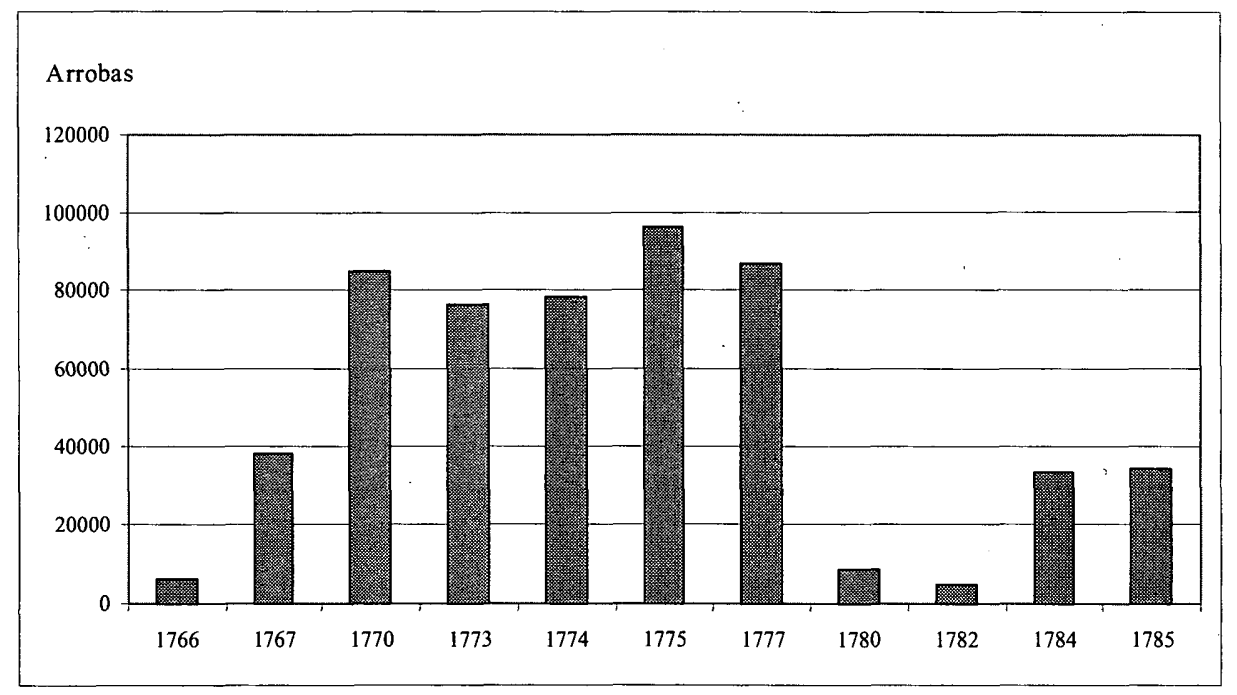

Fuente: Documentación mencionada en nota 4

7 Cubillo, Ramón.: El pescado en la alimentación de Castilla y León durante los siglos XVIII y XIX, León, 1998. Bernardos, José Ubaldo: «El abastecimiento y consumo de pescado en Madrid durante el Antiguo Régimen», Congreso de Historia Económica, Zaragoza, 2001

8 Cubillo, Ramón: Op. cit., 1998.

9 Bernardos, José Ubaldo, op. cit, 2001, p. 14, recoge el origen de la palabra «lengua» como derivación de «lins».

Hispania, LXIV/2, núm. 217 (2004) 601-636 
El destino de este pescado es muy variado, ya que la ubicuidad es el rasgo más destacado de su presencia, pues su conducción se registra hacia los lugares más pequeños, a veces con cargas escasas, rebasando los territorios de la antigua Corona de Castilla hacia Zaragoza, e incluso se envía a La Habana (Mapa I). Si se recurre, como referencia, al año de apogeo de toda la serie disponible, 1775 , que no es el de la mayor diversidad de destinos, se observa que Reinosa es un núcleo preferente donde llega más del 16 por ciento de la cantidad movilizada, previsiblemente, en buena parte, de forma transitoria, ya que la localidad constituía a su vez, un centro de encuentro de arrieros y transportistas 10 que se desplazaban no sólo por la Franquicia santanderina, sino también hacia el sur de la Montaña, adentrándose en las tierras de Castilla, donde por la continuidad en la recepción de partidas, habría que mencionar a Valladolid, Palencia, Cantalapiedra, otro centro de redistribución del Antiguo Régimen en tierras salmantinas, superando cada una de ellas las 1.000 arrobas, cantidad que no satisface las necesidades totales en muchos $\operatorname{casos}^{11}$.

Simultáneamente, la capital del Reino recibía poco menos del 2 por ciento del total aduanado ese año en Santander, lo que resultaba un escaso aporte desde la vía montañesa, no en vano parece que la principal fuente de abastecimiento a la Corte era Bilbao ${ }^{12}$. Además de bacalao, cuya hegemonía es irrefutable se comercia con otros pescados procedentes de capturas de pescadores del Cantábrico como el salmón, distribuido por las poblaciones del ámbito frecuentado por el primero, sardinas, lampreas, rabas, arenques, anchoas, congrio, tanto frescos como cecial y escabechados.

Por su parte el azúcar, aunque con trayectoria irregular, va aumentando la cantidad de sus cargazones, explicable por la relación preferente de Santander con $\mathrm{Cuba}^{13}$ (Gráfico II), que le otorgará el liderazgo azucarero entre los puertos cantábricos, ya que en 1777 expresa valores comparables a los registrados en La Coruña de los años setenta y desde 1783 la supera, puesto que el otro puerto habilitado en 1765 en el Cantábrico, Gijón, no pasará de recepciones mo-

10 MARURI, Ramón: «La burguesía de Cantabria en el siglo XVIII» en La Burguesía española en la Edad Moderna, tomo III, Valladolid, 1992, p. 1296. Centro de comercialización donde a los tres comerciantes estables se añadían 29 carreteros profesionales y 846 campesinos convertidos estacionalmente en transportistas.

11 Miguel, Isabel: El comercio de Castilla y León al final del Antiguo Régimen, Valladolid, 2000, pp. 179-180, pp. 246-249, se dispone de ejemplos de consumo de bacalao en localidades y en monasterios. Así, en Astorga, con poco más de 2800 habitantes, parece que se consumían 1000 arrobas al año, mientras que los monasterios de monjes de la provincia de León duplicaban esa cantidad.

12 Bernardos, José Ubaldo: Op. Cit., 2001, p. 15, y en la p. 11, el autor indica que en 1789 el consumo de bacalao en la capital era de $51.383,75$ arrobas ( 590.913 kilos).

13 Miguel, Isabel: Op. Cit., 1992, p. 163. Este producto llega a representar entre la mitad y a veces los cuatro quintos del valor de todos los efectos introducidos en. Santander desde América entre 1778 y 1785 . 
destas ${ }^{14}$. En efecto, en el transcurso de los años contemplados, $1784 \mathrm{y}$, sobre todo, 1785 ofrecen un desplazamiento de mercancía que rompe el nivel de contingentes anteriores, anunciando la tendencia que presentará, con diversos avatares, en el resto del siglo XVIII y comienzos del siglo XIX ${ }^{15}$.

MAPA I: Destinos de las partidas de bacalao emitidas desde Santander (1775)

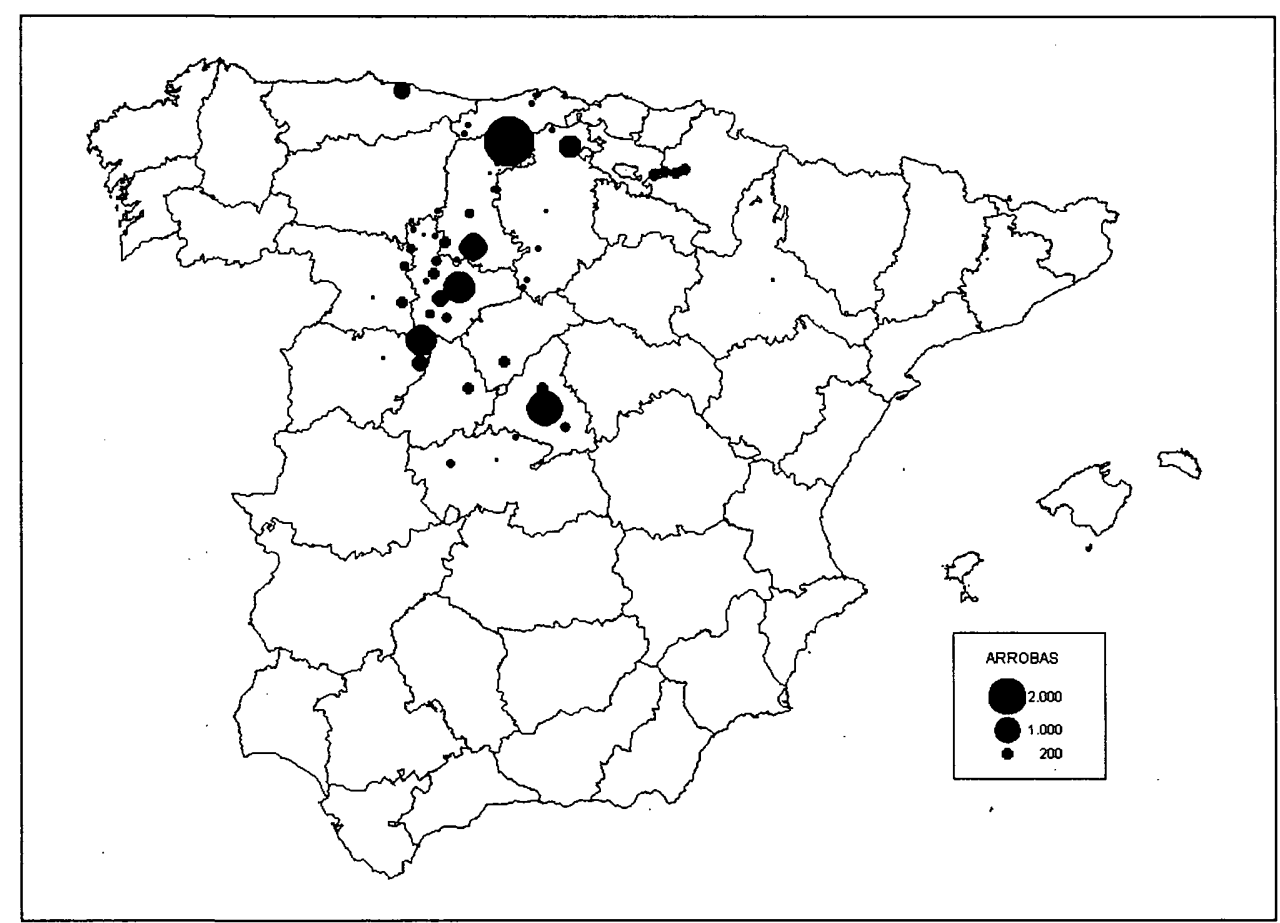

Fuente: Archivo de la Diputación de Burgos, Consulados, Libro R-82.

Nota: También se transporta a La Habana y no es el año de destinos más diversos.

14 MeIjIDE, Antonio: El puerto de La Coruña en el siglo XVIII, La Coruña, 1984, p. 100, en 1768 se desembarcaron en La Coruña 31.745 arrobas, en 1769 se registraron 46.541, en 1770 fueron 91.822, en 1771 resultaron 74.830 arrobas. Miguel, Isabel: Op. Cit. 1992, p. 119, Gijón no supera las 10.000 arrobas de azúcar recibidas, excepto en 1785 y 1789 .

15 Miguel, Isabel: Op. Cit. 1992, p. 164, el azúcar recibido en Santander alcanza su ápice en 1786 y 1790 , al representar en ellos la tercera parte del total extraído de la isla antillana

Hispania, LXIV/2, núm. 217 (2004) 601-636 
Durante el periodo considerado los enclaves más frecuentados fueron Reinosa, Bilbao, San Sebastián, Madrid, Valladolid, Palencia, Burgos, San Ildefonso, El Escorial, e incluso dos enclaves con relación cubana (Gijón y La Coruña) (Mapa II-A), si bien los dos puertos vascos superan la gran cuantía de Reinosa en 1785, aunque la localidad del Alto Campoo se confirma como núcleo redistribuidor en 1785 con 26.838 arrobas movilizadas, pero San Sebastián y Bilbao reciben 53.507 y 25.107 arrobas, respectivamente, incluso en ese año, además, se reexpide a Montevideo y anecdóticamente dos arrobas a Cádiz, el principal puerto peninsular receptor del producto ${ }^{16}$.

Además de las partidas con destino preciso, en la documentación se recogen otras cantidades más pequeñas distribuidas por arrieros y transportistas de muy diversos orígenes, cuyo rastreo a través de la geografía ofrecen una imagen complementaria de la amplitud territorial por la que se mueve el azúcar mencionado (Mapa II-B), reforzando la de los desplazamientos del mapa II-A, a lo largo de un eje norte-suroeste que será constante en el comercio de la meseta norte ${ }^{17}$.

GRÁFICO II: Azúcar comercializada desde Santander

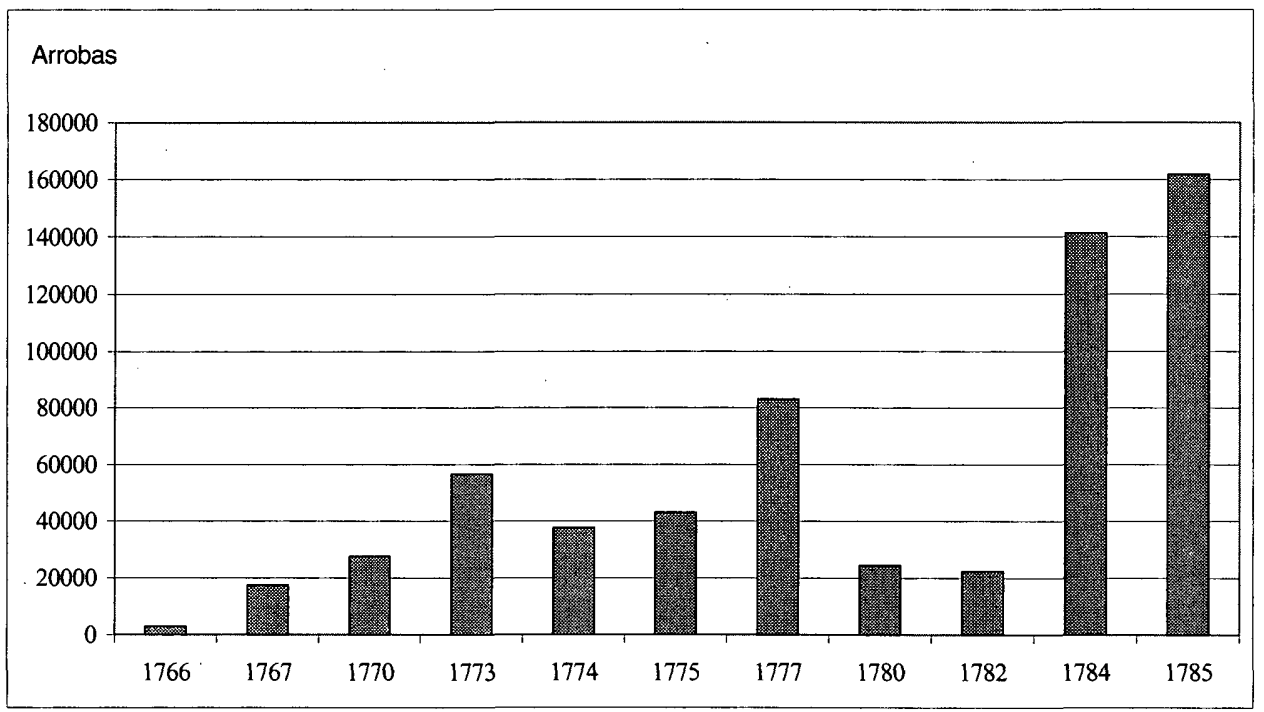

Fuente: Documentación mencionada en nota 4.

16 García-Baquero, Antonio: Cádiz y el Atlántico (1717-1778). El comercio español bajo el monopolio gaditano, Sevilla, 1976.

17 Miguel, Isabel: Op. Cit. 2000, pp.86-88 
MAPA II-A: Destinos de las partidas de azúcar emitidas desde Santander (1785)

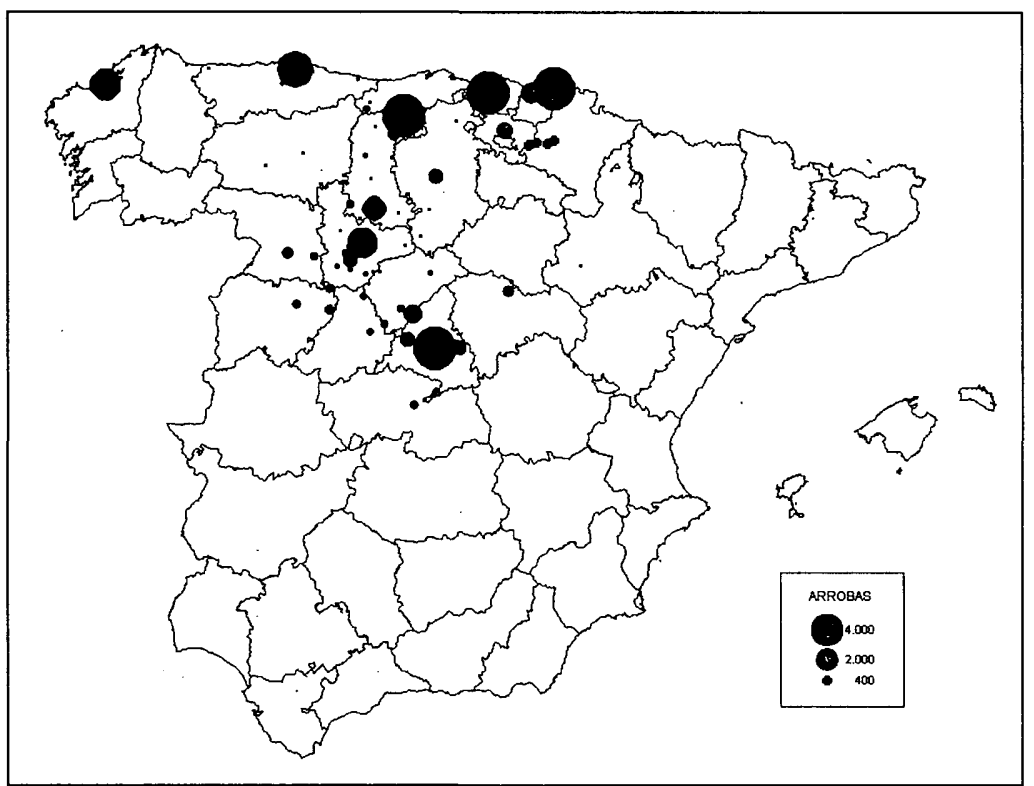

MAPA II-B: Vecindad de los transportistas de azúcar desde Santander (1785)

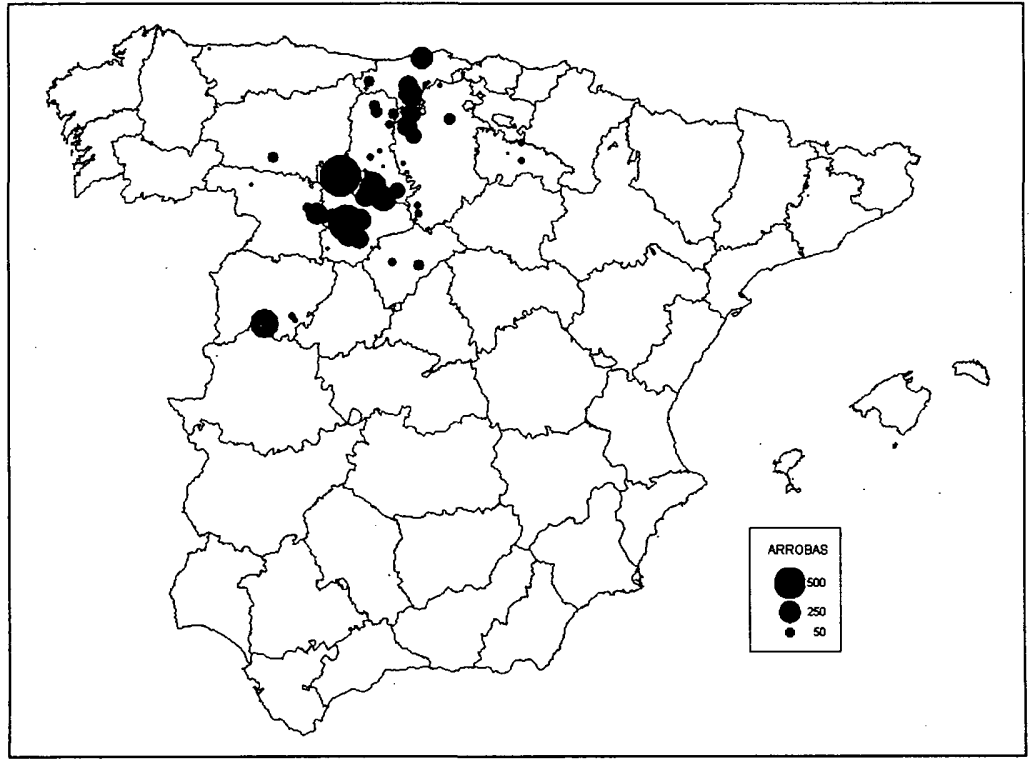

Fuente: Archivo de la Diputación de Burgos, Consulados, Libro R-84.

Hispania, LXIV/2, núm. 217 (2004) 601-636 
El otro producto colonial habitual era el cacao que procedía de la relación santanderina con la Capitanía Venezolana, pero también se registra el denominado de Guayaquil ${ }^{18}$. Durante estos años el puerto cántabro tuvo la competencia de la Compañía de Caracas $^{19}$, cuyo monopolio se desmonta tras la publicación del Reglamento de Libre Comercio de 1778, aunque con sus desembarcos en Pasajes y Cádiz, siguió gozando de protagonismo. Sin embargo, a partir del hiato de la guerra de Independencia de Estados Unidos y sus efectos en el tráfico atlántico, Santander refuerza su posición desde 1782, culminando en nuestra serie claramente en 1785 (Gráfico III) en una tendencia que le llevará, incluso, a rebasar el valor de las cargazones dejadas en Pasajes, en $1789^{20}$.

Este cacao tiene como principales destinos especificados, entre otros, Reinosa, Bilbao, Valladolid, Palencia, Madrid, Segovia, donde se anotan partidas casi todos los años considerados (Mapa III-A). No obstante, la diversidad se acentúa en los años ochenta, sobre todo en 1784 y 1785 , cuando la multiplicidad de centros receptores es mayor y ello sin contar las cargas más pequeñas, que sin destino prefijado, eran conducidas por los arrieros para darles salida en cualquier lugar de su trayecto, además de vecinos de distintos lugares que lo transportaban, ratificando, de ese modo, los ejes de distribución ya sugeridos (Mapa III-B). En relación con el cacao los registros de chocolate desde Santander ofrecen notable similitud en su desplazamiento (Mapa IV).

GRÁFICO III: Cacao distribuido a través de Santander

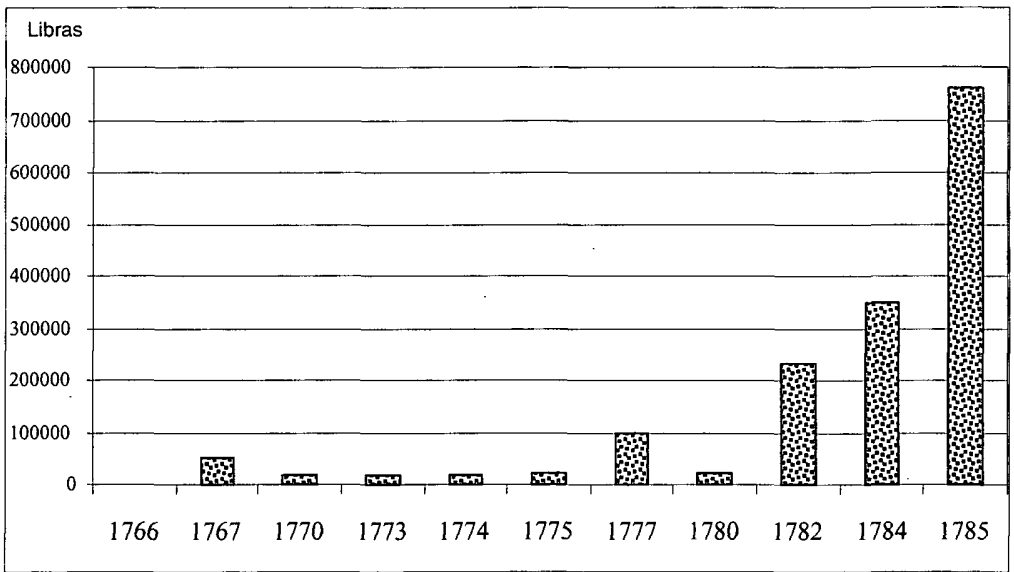

Fuente: Documentación mencionada en nota 4.

18 Miguel, Isabel: Op. Cit. 1992, p. 165.

19 GÁrATE, Montserrat: La Real Compañía Guipuzcoana de Caracas, San Sebastián, 1990

20 Miguel, Isabel: Op. Cit., 1992, p. 213. Año en el que el valor del cacao desembarcado en Santander alcanza casi los 10 millones de reales de vellón, en tanto que el dejado en Pasajes había caído a los 6 millones de reales de vellón. 
MAPA III- A: Destinos de las partidas de cacao emitidas desde Santander (1785)

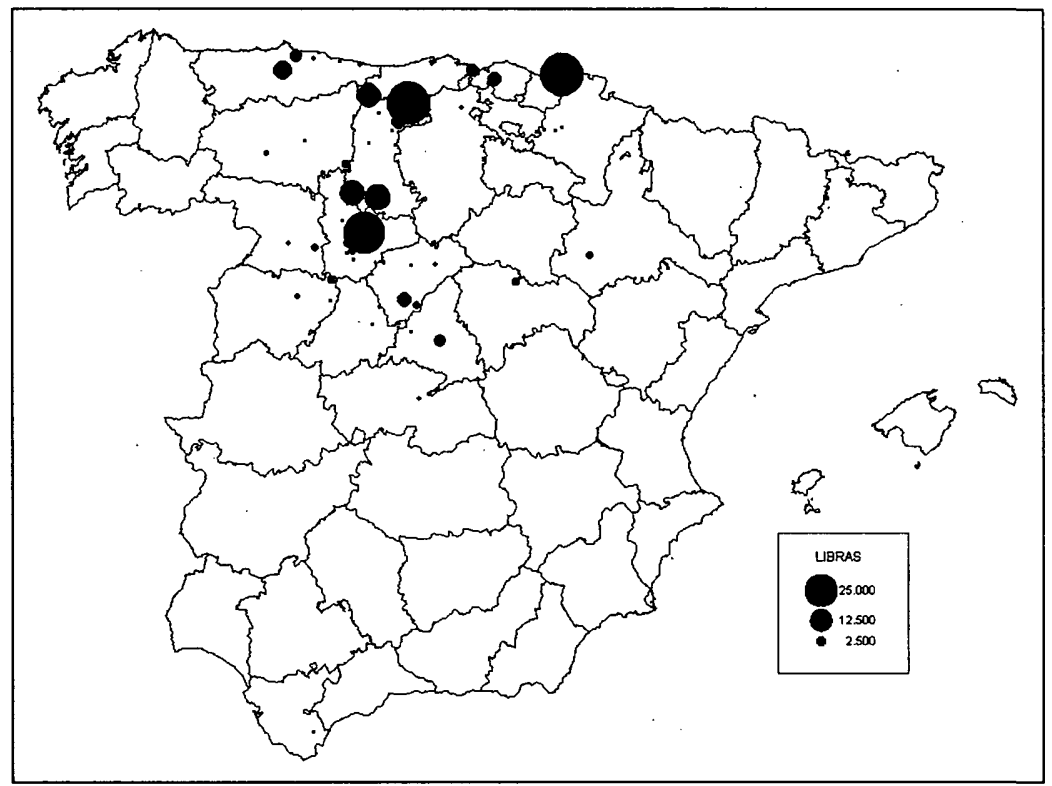

MAPA III-B: Vecindad de los transportistas de cacao desde Santander (1785)

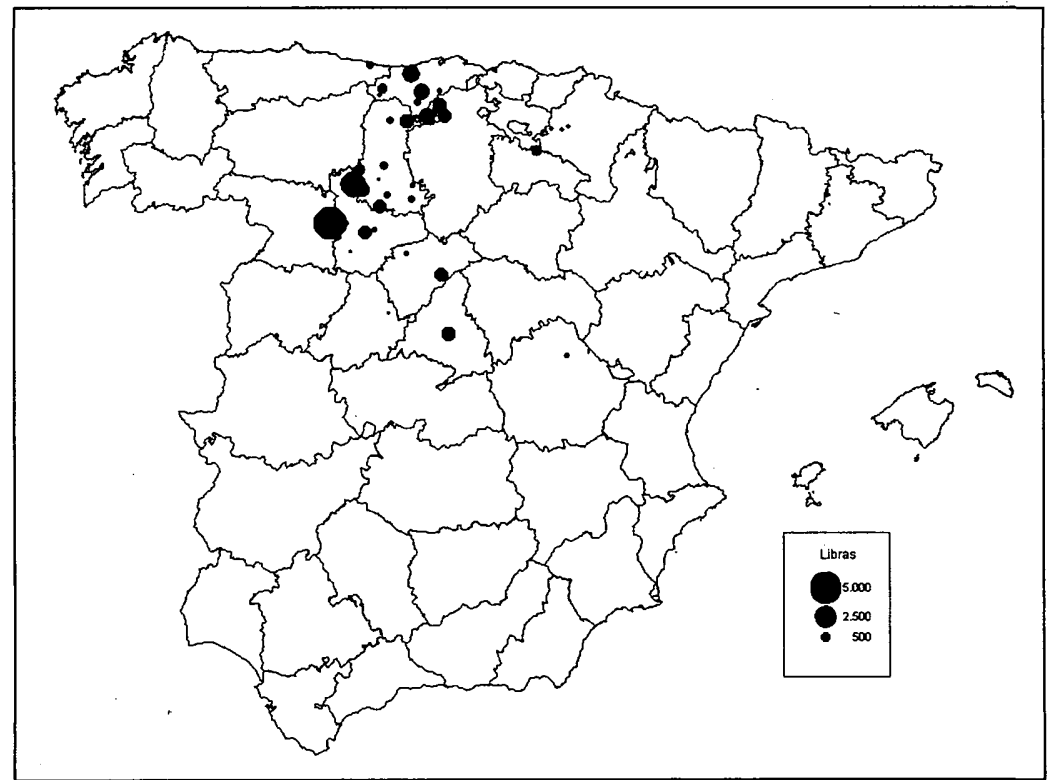

Fuente: Archivo de la Diputación de Burgos, Consulados, Libro R-84.

Hispania, LXIV/2, núm. 217 (2004) 601-636 
MAPA IV: Destinos del chocolate emitido desde Santander

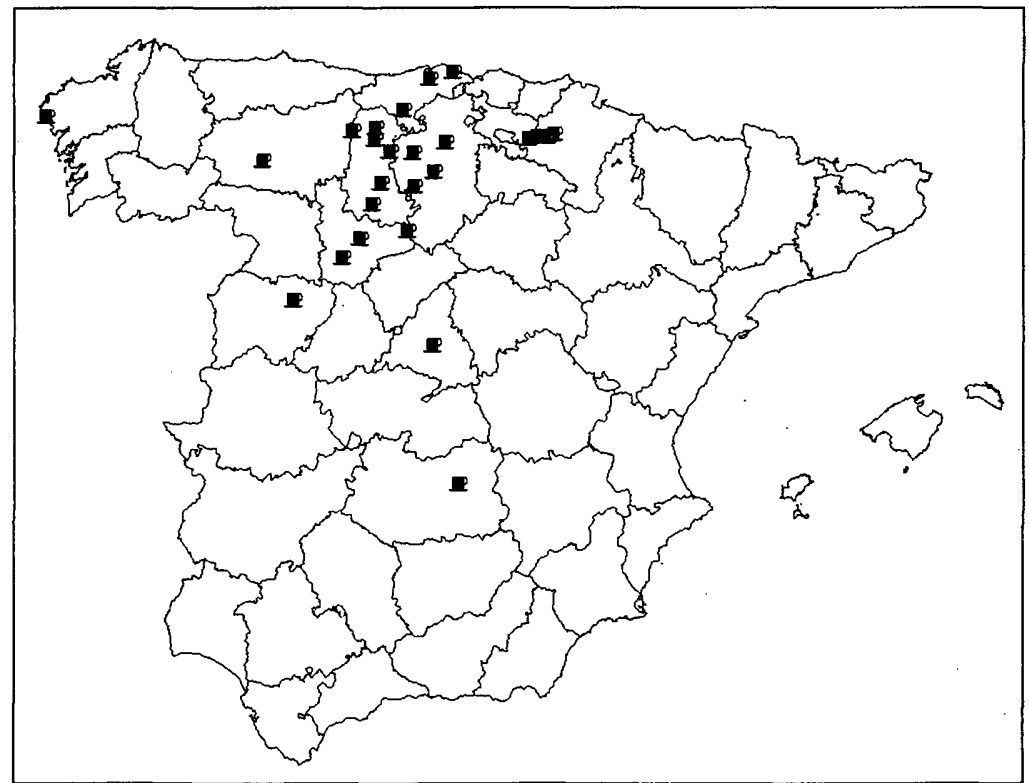

Fuente: Documentación mencionada en nota 4

Los tres productos destacados fueron los más abundantes y frecuentes, pero la gama de alimentos resultó ser muy diversa. Entre los coloniales (Cuadro I), la canela de Holanda, procedente de sus posesiones ultramarinas, siempre presente, con partidas más equilibradas anualmente, sobresale en 1767, 1770, 1773 y se destina, sobre todo, a Madrid, Burgos y menos a Valladolid, Reinosa, San Ildefonso y El Escorial, si bien son varias las localidades que en alguno de los años reciben esta mercancía ${ }^{21}$. Más cuantiosa resulta, en ocasiones, la pimienta de Holanda y la de Tabasco, siendo más abundante la primera especialmente en 1773 y 1785 , cuyas partidas, sin destino específico, son transportadas habitualmente por mujeres de San Pedro y La Vega, es decir pasiegas, al igual que sucede con el clavillo, mientras la nuez es poco representativa en el conjunto. La pimienta se envía a Madrid, Burgos, Reinosa y poco a Valdemoro, pero también se reexpide a La Habana. En cuanto al café, procede esencialmente de Martinica y se conduce mayoritariamente a Madrid, si bien se anotan algunas

21 Tal es el caso de La Coruña con 1566 libras en 1773, Alcalá con 339 libras en el mismo año, Valdemoro con 486 libras en 1770, y otras cantidades más pequeñas que llegan a Chinchón, Illescas, Sigüenza, Segovia, Dueñas, Villarramiel, La Habana, San Francisco de Campeche y al monasterio de San Andrés del Arroyo. 
cargas a Palencia, Bilbao, Ávila y. San Sebastián y se reexporta a Amsterdam, mientras el te resulta anecdótico.

CUADRO I: Especias y bebidas coloniales comercializadas desde santander (Libras)

\begin{tabular}{|l|c|r|r|r|r|r|r|r|r|r|c|}
\hline & 1766 & 1767 & 1770 & 1773 & 1774 & 1775 & 1777 & 1780 & 1782 & 1784 & 1785 \\
\hline Canela & 3 & 10.547 & 12.085 & 10.382 & 9.942 & 5.365 & 7.992 & 3.244 & 4.555 & 5.832 & 6.915 \\
\hline Clavillo & 1 & 1.041 & 2.556 & - & 1.589 & 2.489 & 1.451 & 35 & 20 & 1.938 & 3.059 \\
\hline Pimienta & - & 23.171 & 3.263 & 12.724 & 16.944 & 18.944 & 8.078 & 723 & 532 & 3.663 & 15.222 \\
\hline Nuez & - & - & 826 & - & 35 & - & - & - & 220 & - & - \\
\hline Café & - & - & 5.038 & 8 & 187 & 69 & 181 & - & 50 & - & 625 \\
\hline Te & - & - & 2 & - & 4 & - & - & - & - & - & - \\
\hline
\end{tabular}

Fuente: Documentación mencionada en nota 4.

Además de los alimentos referidos de origen exterior se movilizan otros muchos en menor cuantía, tanto del Reino como foráneos. Así, la harina de la Montaña, procedente de las fábricas de Campuzano y de la Compañía de Longistas $^{22}$ se anota en los registros santanderinos, junto a la denominada de «Castilla» o del «Reino», aunque con la irregularidad que provocan las crisis de subsistencia que retraen su extracción (Gráfico IV). En estos casos de precariedad es sustituida por la importada de Filadelfia en 1775 y $1785^{23}$, con protagonismo relevante sobre el total de harina exterior en las cargazones que se destinan a América ${ }^{24}$, y por la de Francia, en 1784 y 1785. De manera que, a lo largo del periodo analizado, en torno al 40 por ciento de la harina contabilizada procedió de Francia, el 35 por ciento de Filadelfia y el resto era obtenida en las fábricas de la Montaña. El destino preferente fue La Habana y también Ferrol, aunque en los años ochenta se orienta a otros puertos del Cantábrico y a Cádiz, realzando la

${ }^{22}$ Miguel, Isabel: Op. Cit 1992, p.142

23 BARREDA, Fernando: Comercio maritimo entre Estados Unidos y Santander (1778-1829), Santander, 1950 , p. 7 , indica que era importada por mercaderes santanderinos y se destinaba casi totalmente a reembarcarla para La Habana.

24. Miguel, Isabel: Op. Cit. 1992, p.143, ya que la harina de Filadelfia fue el 45,8 por ciento en 1784 y el 36,4 por ciento en 1785 del total llevado a América desde Santander. IBIDEM: «Presencia palentina en el comercio hispanoamericano» en Publicaciones de la Institución Tello Tellez de Meneses (Palencia) 61 (1990). IBIDEM: "Comercio de Castilla y León con América a través de los puertos cantábricos, 1786-1818» en Cuadernos de Economía de Castilla y León (Valladolid) 2 (1992), pp. 158-159: La harina palentina comienza su andadura americana en 1787 desde la fábrica que Francisco Durango instaló en Monzón de Campos. MORENO, Javier: «La producción de harinas en Castilla la Vieja» en Revista de Historia Económica, (Madrid) 2, (1995) pp. 228-250. 
función redistribuidora del abra montañés (Cuadro II), que corroboran simultáneamente los diversos cereales del Reino en el aduanados (Cuadro III).

\section{GRÁFICO IV: Harina comercializada desde Santander}

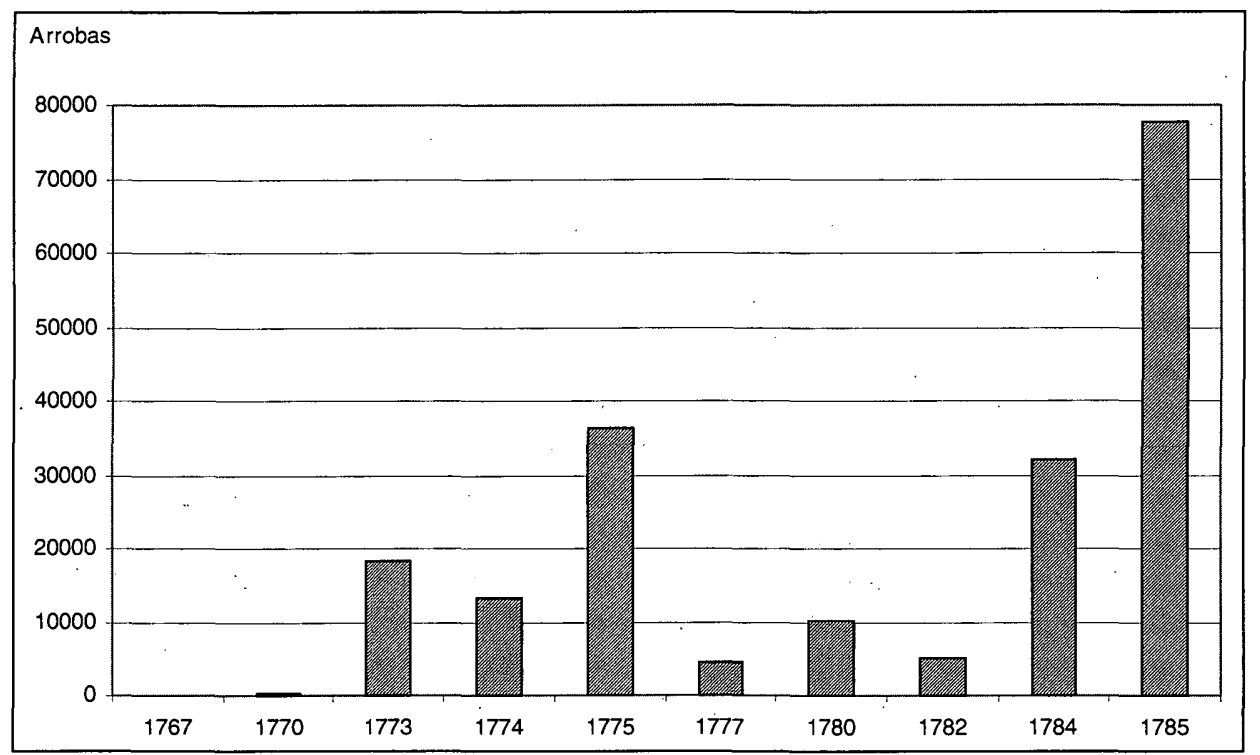

Fuente: Documentación mencionada en nota 4

CUADRO II: Destinos frecuentados por la harina distribuida desde Santander (arrobas)

\begin{tabular}{|l|c|c|c|c|c|c|c|c|c|c|}
\hline & 1767 & 1770 & 1773 & 1774 & 1775 & 1777 & 1780 & 1782 & 1784 & 1785 \\
\hline Ferrol & 90 & 188 & 732 & 1.860 & - & 15 & 216 & 2.708 & 603 & 6.130 \\
\hline La Habana & - & - & 17.528 & 11.503 & 27.824 & 4.425 & - & - & 13.095 & 56.288 \\
\hline La Coruña & - & - & - & - & 8.279 & - & 72 & 2.557 & 3.000 & 8.573 \\
\hline Cádiz & - & - & - & - & - & - & 9.525 & - & 248 & - \\
\hline Málaga & - & - & - & - & - & - & 216 & - & - & - \\
\hline La Guayra & - & - & - & - & - & - & - & - & 4.230 & 3.090 \\
\hline Pasajes & - & - & - & - & - & - & - & - & 5.175 & 3.750 \\
\hline Bilbao & - & - & - & - & - & - & - & - & 45 & - \\
\hline San Sebastián & - & - & - & - & - & - & - & - & 2.325 & - \\
\hline Orduña & - & - & - & - & - & - & - & - & 2.148 & - \\
\hline
\end{tabular}

Fuente: Documentación mencionada en nota 4. 
CUADRO III: Cereales comercializados desde Santander

\begin{tabular}{|l|c|c|c|c|c|c|c|c|c|c|r|}
\hline & 1766 & 1767 & 1770 & 1773 & 1774 & 1775 & 1777 & 1780 & 1782 & 1784 & 1785 \\
\hline Trigo (fg) & - & 10.843 & 6.033 & 14.217 & 50.458 & 62.877 & 30.949 & 210.380 & 155.197 & 177.059 & 236.196 \\
\hline Cebada (fg) & - & 1.716 & 414 & - & - & 18.020 & 61 & 18.401 & 7.703 & 173 & 75 \\
\hline Maíz (fg) & - & 100 & - & - & - & - & 1.253 & 416 & - & 5.648 & 50 \\
\hline Arroz (@) & - & - & 210 & 673 & 790 & 1.700 & 90 & - & - & 62 & 55 \\
\hline
\end{tabular}

Fuente: Documentación mencionada en nota 4.Fg: fanega. @: arroba

Son, asimismo, frecuentes algunas bebidas como vino, aguardiente y cerveza, sin faltar chacolí que llega al otro lado del Atlántico, anisete, mistela, sidra, zarzaparrilla o diversos licores. El aguardiente, tanto de Francia como de Cataluña, se distribuye puntualmente ${ }^{25}$ y más localizados aún son los destinos de la cerveza extranjera que es reexportada desde el puerto santanderino a La Habana y San Francisco de Campeche ${ }^{26}$. Por su parte, el vino que se comercializa a través de Santander es de origen diverso, pero entre todas las variedades destaca el de Málaga. Este llega al puerto santanderino desde el anduluz ${ }^{27}$ y se distribuye a Reinosa, Potes, Bilbao, San Sebastián, Santoña, Castro, Villaviciosa, Burgos, Valladolid, Palencia ${ }^{28}$, e incluso es transportado a La Habana y San Francisco de Campeche. No faltaron otros vinos sureños como el de Jerez, los Rioja o el castellano de La Nava, así como los franceses de Burdeos y Borgoña ${ }^{29}$.

25 El aguardiente se dirigía a Santoña, La Coruña, Santillana, Bilbao, Comillas, Carrión, La Habana, Salamanca, San Sebastián, y transportado por vecinos de Riocorbo, Laredo, San Vicente de la Barquera, Limpias, San Pedro y Medina.

26 BARREDA, Fernando: «Prosperidad y desarrollo industrial en el siglo XVIII» en Aportación al estudio económico de la Montaña, Santander, 1957, pp. 481-612. Miguel, Isabel: «Pretensión y realidad de la incidencia en Castilla del comercio de Santander con América a finales del siglo XVIII» en Castilla y León en América, Valladolid, 1991, pp. 449-450. La fabricación de cerveza en Santander tiene lugar a finales del siglo XVIII en las instalaciones de José Zuloaga, Antonio del Campo y Clara Lienzo, posteriormente de Pedro González, hasta entonces es importada.

27 Miguel, Isabel: «Productos del Reino de Granada en las cargazones cantábricas rumbo a América (1778-1818)» en El Reino de Granada y el Nuevo Mundo, Granada, 1994, vol. 1, pp. 410-411, 415.

28 Este vino de Málaga es canalizado a otros destinos en sus itinerarios por vecinos de Villaescusa, Arreba, Osorno, Paredes de Nava, Amusco, Escalada, Cevico, Matapozuelos o Villanubla. En todo caso, vecinos de Lantueno, Poza, Gallegos, Cevico y del mismo Santander se encargaban de distribuir estos vinos por el territorio de Castilla.

29 El vino de Jerez se dirigía a Madrid. El denominado vino de Francia se destina a Llanes, Ferrol, Cádiz, Madrid y Burgos, mientras que el vino de Frontiñán llega a Reinosa, Valladolid y Madrid, donde se recibe el de Burdeos y alguna partida de Borgoña. Menos frecuentes son los caldos de Tudela que se transportan hacia Laje y Camariñas, los de Navarra a Ferrol, los de Peralta a Alicante. También se registra vino de La Nava con destino a Bilbao y Ferrol, o de "Castilla» para la Habana, donde llega también el de Rioja, así como a Buenos Aires. En la ciudad rioplatense se recibe el denominado «vino del Reino», que arriba también a San Sebastián, Cádiz, La Coruña y Cuba. 
Este abanico alimentario canalizado por el puerto de Santander se completaba con diversas frutas del Reino (manzanas, naranjas, limones, higos, pasas, ciruelas pasas, almendra, aceitunas), legumbres (alubias y habichuelas hispanas junto a garbanzos de Marruecos), dulces nacionales (confitura, almíbar), productos cárnicos exteriores (carne salada, piernas de ganso), chacinería nacional (jamón, chorizo, perniles de tocino) y queso. Este último procedente de Francia, de Irlanda, de Flandes o de Holanda, destinado con más frecuencia a Madrid, Valladolid y La Habana, dentro de una extensa gama de localidades que se va ampliando a lo largo del periodo analizado ${ }^{30}$.

\section{I.2. Variada gama de textiles extranjeros}

Tras los alimentos, los tejidos constituyen el conjunto con más registros anotados en los libros de asientos estudiados. Su diversidad y el origen extranjero de la mayoría constituyen los rasgos más significativos. Entre ellos las telas de lino y de lana son las dominantes, dejando en posición minoritaria a las de algodón y, sobre todo, a las elaboradas con seda.

El testimonio aduanero permite constatar los diferentes tipos de tejidos de lino, con predominio absoluto de lienzo rosa, seguido de brabante, entre la gama de factura europea ${ }^{31}$, junto a algunos del Reino tanto de lino como de cáñamo ${ }^{32}$. Todos ellos se difunden desde el puerto cántabro a los destinos más variados, sobre todo del cuadrante noroccidental de España, además de algunos enclaves madrileños, Almagro, Cádiz (Mapa V) y a diferentes puertos hispanoamericanos como La Habana, San Francisco de Campeche y La Guayra, más frecuentes estos en los años ochenta, incluso a Nueva Orléans donde se dirige lencería de Tala-

30 Entre las localidades señaladas estaban Burgos, Reinosa, Camariñas, Villacastín, Melgar, Alcalá, Llanes, Herrera, Cantalapiedra, Peñaranda, Ferrol, Corcubión, Potes, Bilbao, San Vicente, Zamora, Palencia, Laredo, Santoña, Herrera, Toro, Frómista, Astorga, Luarca, Ribadesella, Medina del Campo, Villarramiel, Roa, Segovia o Aguilar.

31 De los tejidos europeos, llegan a anotarse 172.449 varas de lienzo rosa en 1774 , su año de apogeo en la serie, mientras el máximo de brabante se observa en 1777 con 83.061 varas. Menos abundantes fueron platilla, cuya mayor cuantía se registra en 1780 con 37.066 varas, y crea que alcanza 28.303 varas en 1780. Continuan en menor medida terlíz de Flandes y Francia, bretaña y morlés, el resto es bastante menos significativo: caserillo, lienzo crudo, bocadillo, trué, cambray, lienzo san Jorge, de Gante, cozneo, vitre, retorta, batista, lona, listados, cotí, pontibi y presilla. Algunos tipos únicamente se registran para destinos americanos, tal es el caso del cholet que sólo se transporta a La Habana en estos años, lienzo Silesia a San Francisco de Campeche, lienzo blanco a San Francisco de Campeche y La Habana. Otras telas se dirigen a lugares en exclusiva como el gante a Madrid, lienzo moscovia a Reinosa, lienzo de Flandes a El Escorial, encerado a Valladolid, Almagro y La Coruña, billuvina a Reinosa.

32 De los tejidos de lino de origen hispano destacan lienzo pintado de Cataluña, no siempre tejido aunque sí pintado en el Principado, embarcado a Ribadesella y a Gijón, lienzo Jáñiz a Buenos Aires. Junto a ellos los tejidos bastos de cáñamo para Madrid, San Francisco de Campeche, La Habana, Ferrol, Toledo, Villaviciosa, Reinosa, arpillera a Comillas y Reinosa y márraga a Burgos. 
vera. Además de las piezas de tela de la fibra indicada, se registran confecciones lenceras del Reino, Flandes y Francia, anotadas fundamentalmente en los años setenta, puesto que en la década posterior, apenas se encuentran ${ }^{33}$.

MAPA V: Destinos habituales de las telas de lino emitidas desde Santander

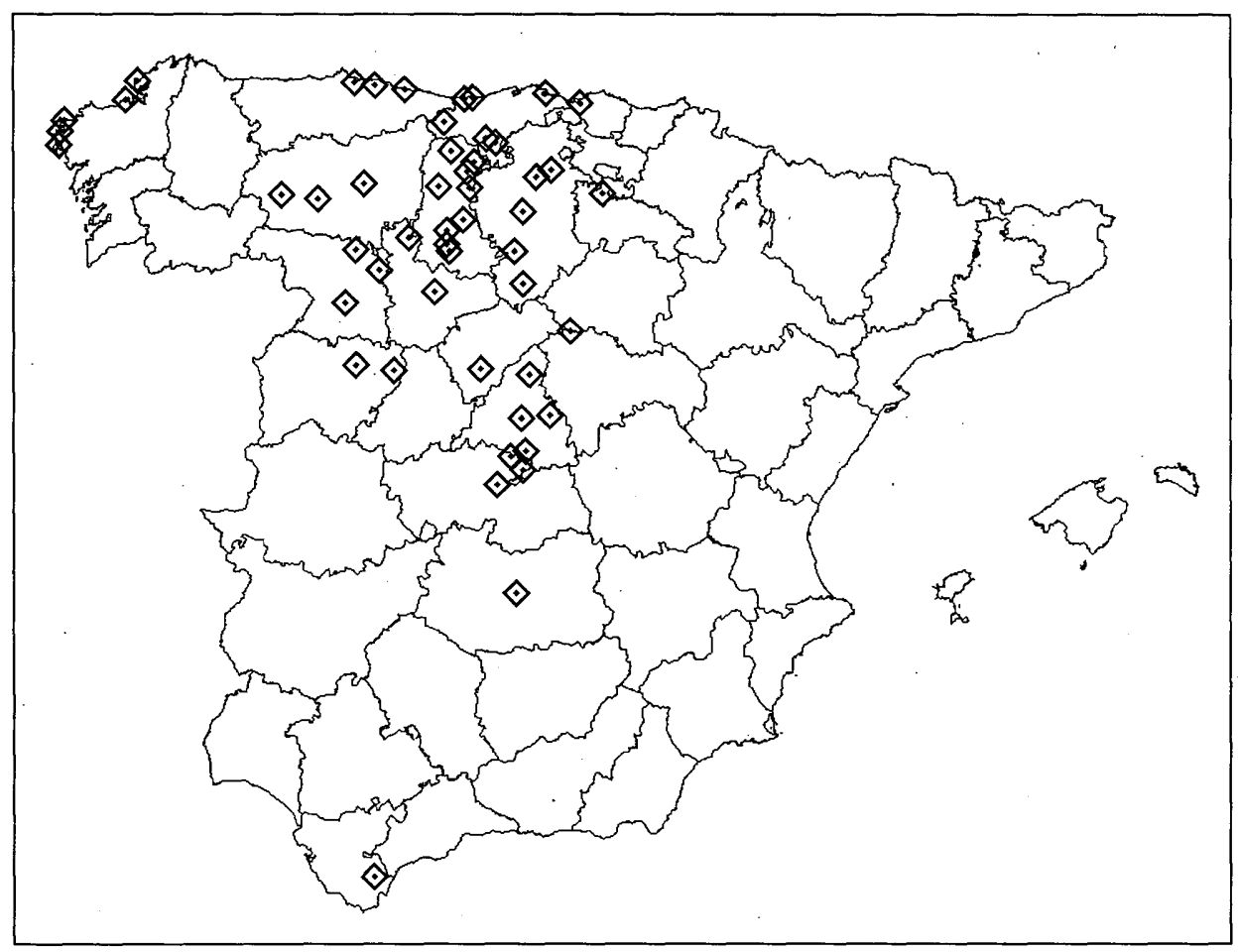

Fuente: Documentación mencionada en nota 4

Nota: También se envían a La Habana, Campeche y La Guayra.

33 En este sentido, hay que mencionar los pañuelos de lienzo elaborados en Soria, los de bretaña y los de hilo que se dirigen a Frómista, Valdemoro, Burgos, Valladolid, San Francisco de Campeche, Camariñas, Almagro y a La Habana, puerto al que llegan también los de cambray y de cholet. Igualmente reseñables son las medias de lino que se destinan a La Habana o las calcetas de hilo que acuden a San Francisco de Campeche, al tiempo que se anota la presencia de camisas de lienzo para Valladolid y La Habana, destino este último al que se envían camisolas y calzones de terliz, de crea, true o bretaña. Precisamente la isla antillana es, en la misma década, lugar de arribada de mantelerías y servilletas de Francia y de delantales de cambray. También se observan anotaciones sobre vuelos de encaje y encajes de Flandes para Madrid o la presencia de colchas y alfombras de hilo, peinador de lienzo para Valladolid, sin olvidar cintas de hilo de Flandes para Valdemoro y Burgos e incluso distintos tipos de hilo, en los ochenta, procedentes de Córdoba o de Asturias y cordones de hilo. 
Simultáneamente, los tejidos de lana, a pesar de ser la fibra nacional por antonomasia, proceden mayoritariamente del exterior. Entre ellos sobresale claramente la serafina de Francia, que casi dobla a su seguidora la estameña originaria del mismo país o la bayeta, predominantemente gala, tanto miliquín como alconcher ${ }^{34}$, aunque menos cuantiosa que las dos primeras variedades, pero enormemente difundida entre una gran diversidad ${ }^{35}$, que frecuenta el puerto santanderino como ha podido constatarse por otras fuentes de la épo$\mathrm{ca}^{36}$. No faltaron en los registros aduaneros un poco de bayeta de Palencia embarcada para Asturias y algunos paños denominados de "Castilla», de Tarazona, Prádanos, Brihuega, Chinchón y Segovia o sayal «del Reino». A las telas referidas se sumaban artículos elaborados de lana y de estambre de Francia ${ }^{37}$ y cobertores, estos últimos fabricados en Palencia y dirigidos a La Habana, La Coruña, Corcubión, Laredo, Colindres, Camariñas, San Sebastián.

Su distribución desde Santander presenta bastante ubicuidad, mayor que la de los lienzos, como puede apreciarse en el mapa VI, donde, exceptuado el territorio americano, se localizan los destinos preferentes de los mencionados tejidos laneros, mostrando al mismo tiempo no sólo la función redistribuidora del citado puerto a otros enclaves del Cantábrico y hacia América, sino también la competencia con la producción del Reino en las zonas abastecidas del interior de la meseta norte y la capacidad de penetración mediante redes de comercialización que llegan a la meseta sur, a localidades de ferias, como Almagro, y a Aragón.

En cuanto a los tejidos de seda, resultan intermitentes en su desplazamiento y escasos en cantidad. Son habitualmente de origen hispano, ante la protección de que disfrutan y entre ellos se mencionan con denominación propia los rasos de Requena que van a Ferrol y a La Habana. No obstante, existen variedades extranjeras, sobre todo de Francia, que se envían a diferentes núcleos del interior y a Canarias ${ }^{38}$. Simultáneamente, se comercia con diversas prendas de

34 La serafina alcanza el máximo de la serie en 1773 con 26.277 varas, la estameña llegó a tener su apogeo en 1767 con 30.045 varas, pero después decae, en tanto que la bayeta miliquín se alza a las 10.306 varas de 1780 y la de alconcher a las 11.127 en 1775 .

35 También resultan destacadas de origen extranjero sempiterna, sarga, camelote de pelo y de lana, calamaco, cordellate y lamparilla. El resto de las numerosas variedades extranjeras se reducen drásticamente, tal es el caso de monfort, tripes de lana, droguete, anascote, angulemilla, barraganes, arretines o ratina, rayadillo, florestas, filipichin, calamandria, paño de Carcasona, velillo, damasco de lana, principela, paño de Sedán, bayetón, boeuf, griseta, castorcillo, catalufa de hilo y lana. Ciertos tipos muestran preferencia por ámbitos americanos como beaufort, drape y paño de Inglaterra, Holanda y Normandía destinados a La Habana, a donde se envían también medios paños de Inglaterra, escarlatina, durois, chalon y beatilla

36 Miguel, Isabel: Op. Cit. 2000, p.68

37 Se trataba de gorros de lana, redes y cintas (rebenas, santa Isabel, belduque), junto a calzones, casacas, orillos. No están ausentes incluso los sombreros de vicuña para Corcubión junto a los de castor de Francia.

38 Tal es el caso del tafetán destinado a Astorga y La Habana, la rasilla para Valdemoro, el bocarán a Palencia y Reinosa, la belisamina, el terciopelo, el carro de oro para Saldaña, el cotí de seda a 
seda francesas integrantes del atuendo personal, doméstico o eclesiástico ${ }^{39}$, cuyos destinos son fundamentalmente Madrid y La Habana y en alguna otra ocasión Valladolid, Salamanca, Astorga, Paredes de Nava, Burgos, Oviedo, Reinosa y Bilbao.

MAPA VI: Destinos de los tejidos de lana emitidos desde Santander

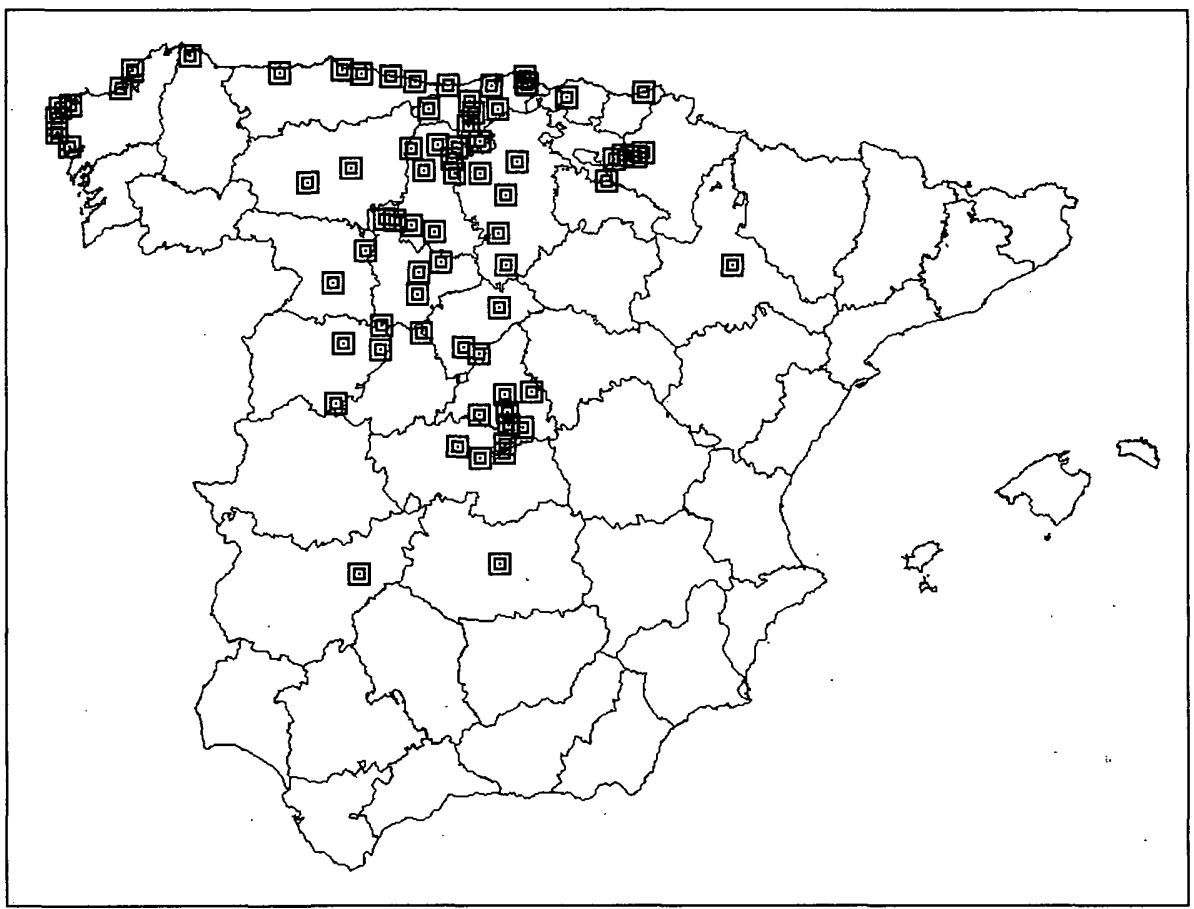

Fuente: Documentación mencionada en nota 4

Sin embargo, eran las telas de algodón las que disponían de un atractivo cada vez mayor en la época, aunque la posibilidad de concurrencia con la producción catalana impidió reiteradamente la presencia de las extranjeras, cuyas

\footnotetext{
Valdemoro, los damasquillos y brocatos para Burgos, bocací para Canarias y el bombasi para Reinosa o simplemente «tela de seda» a Grijota

39 Se trata de calzones, gorros, pañuelos, casullas, guantes, bolsas, medias, redes, ligas, cordones y cintas originarias de Francia. También se emiten quitasoles, gorros y bolsas de tafetán, vestidos de grodetur, colgaduras de cama en damasco, chupas bordadas de oro o de carro de oro y en punto de seda, casaca de terciopelo, gorgorán pintado e incluso alguna colcha de China, deshabillés, encaje de oro, cofias de blonda y blondas, aunque también cintilla de roca de Andalucía,
}

Hispania, LXIV/2, núm. 217 (2004) 601-636 
calidades eran requeridas en el Reino ${ }^{40}$. En estas circunstancias, el flujo de los tejidos foráneos registrados durante el periodo analizado responde a los rasgos de irregularidad provocada por las restricciones legislativas observadas en otros estudios $^{41}$, al margen de que el contrabando proporcionara la ocasión de adquirirlos en el mercado interior. Entre las variedades de origen europeo transportadas destaca el ruan, sobre todo por la cantidad comercializada en 1785 que rompe las medias de los años anteriores ${ }^{42}$, seguido muy lejos por cotonía, laval y bolanda, de manera que los demás tipos resultan muy episódicos: muselina, prohibida intermitentemente, tripe, lienzo nubado o estopilla de algodón, terciopelo de algodón, coton nubado, cotoneta. Junto a las modalidades extranjeras se encuentran algunas calidades nacionales procedentes de las fábricas de Catalu$\tilde{\text { ñ }}{ }^{43}$ como indiana, zangaletas, mitan, franela, muletón y estampados ${ }^{44}$.

La difusión de los tejidos de algodón desde Santander ofrece rutas y destinos similares a los hasta ahora detectados en los tejidos de lino y lana, aunque con menor dispersión (Mapa VII), hasta el punto de que los de origen catalán, aduanados en este puerto, tienen preferencias reiteradas: Llanes, Reinosa, Gijón, Burgos, Astorga ${ }^{45}$.

\section{I.3. Recursos para la actividad productiva}

El conjunto de mercancías aludidas se acompaña de otra variada gama de las destinadas a mantener en funcionamiento los distintos sectores productivos, aunque su posición relativa es menos significativa en los registros.

En este sentido, es preciso aludir a las materias primas industriales no alimentarias y semielaborados entre las que destacan los inputs dirigidos a las tenerías, especialmente los cueros al pelo. Este producto incrementa extraordinariamente su participación en los años ochenta del siglo XVIII ${ }^{46}$, precisamente cuando La

10 Miguel, Isabel: Op. Cit. 2000, pp. 182-185, sobre la inclinación a los tejidos de algodón en el territorio de la actual Castilla y León.

41 Miguel, Isabel: Op. Cit. 2000, pp. 71-73.

12 En este año de 1785 se registran 239.335 varas de ruan en Santander, muy superiores a las 23.000 o 27.300 de 1773 y 1774 respectivamente.

13 SÁNCHEZ, Alejandro: "La era de la manufactura algodonera en Barcelona, 1736-1839» en Estudios de Historia Social (Madrid) $48-49$ (1989) pp. 65-113. THOMPSON, James: Els origens de la industrialització a Catalunya: el cotó a Barcelona, 1728-1832, Barcelona, 1994. MiguEL, Isabel: Perspicaz mirada sobre la industria del Reino. El Censo de Manufacturas de 1784, Valladolid, 1999, pp. 292-294.

亿1 Además se canalizan en 1770, colchas de algodón, medias y vueltas de muselina a La Habana, Madrid y a la feria de Colindres, así como pañuelos de muselina y de algodón a Castilla,

is Miguel, Isabel: Op. Cit. 2000, pp. 148 y 230, en Astorga, los Baylina, Manuel García Durango, Gregorio Pérez Villamil y Miguel Portius son algunos de los comerciantes de tejidos de esta época, mientras en Burgos los Domínguez de la Torre y Manuel García Hoyuelos son habituales del ramo.

16 Como referencia, en 1777 se recibieron en Santander 6.285 cueros al pelo, pero en 1784 fueron 49.119 y en 1785 resultaron 37.788 , a los que habría que añadir en cada año los expresados en arrobas y paquetes. 
Coruña, que había tenido el liderazgo receptor del norte hispano por su estrecha relación de Correos con los puertos rioplatenses, comienza a ver disminuir la cuantía de $\operatorname{estos}^{47}$ y en Gijón no desembarcaban en estos años. Procedían, sobre todo, de Buenos Aires, pero con ciertas partidas de Portugal y varias del país, preferentemente de la Montaña. Se distribuyen profusamente, pero fueron Bilbao, Reinosa y en menor medida, Melgar de Fernamental, Marrón, San Sebastián y Sepúlveda, los centros más destacados por la cuantía recibida durante el periodo analizado, sin olvidar otros enclaves fuera del Reino como Bayona, Burdeos, Ostende o Londres (Mapa VIII). Precisamente en Povedal de Marrón y Melgar se reciben también cueros de ternero curtidos, pieles de gato y de terneros salados y pieles secas de terneros extranjeros así como cueros de buey de la Montaña, aunque estos últimos se orientan, en ocasiones, también a Burgos y Bilbao, mientras de carnero y cueros curtidos cántabros llegan a Ferrol.

MAPA VII: Destinos habituales de los tejidos de algodón emitidos desde Santander

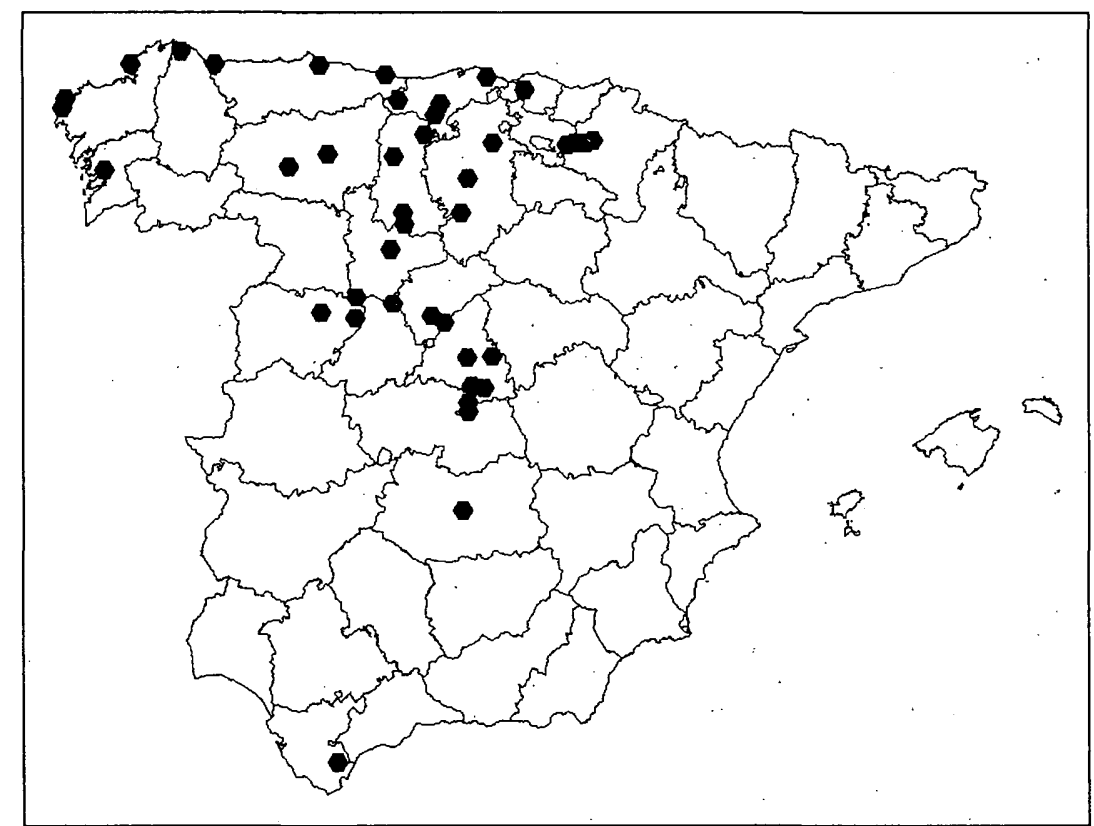

Fuente: Documentación mencionada en nota 4

47 Meijide, Antonio: Op. Cit. 1984, p. 102. Alonso, Luis: Comercio colonial y crisis del Antiguo Régimen en Galicia, 1778-1818, Santiago, 1986. AlONSO, Luis: "Comercio gallego entre 1764 y 1820. Estado de la Cuestión» en Comercio Libre entre España y América Latina, 1765-1824, Madrid, 1987, La Coruña recibe en 1784, 24.091 cueros y en 1785, 20.571.

Hispania, LXIV/2, núm. 217 (2004) 601-636 
Asimismo, las tenerías se abastecen vía importación, a través de Santander, de grasa de ballena, entre otras, la fábrica de Diego Tomé en Melgar de Fernamental ${ }^{48}$, donde entra al mismo tiempo grasa de venado, «borra de aceite»y "grasa de sardina", si bien otros destinos anotados son el Canal de Castilla, Herrera, Madrid, Burgos, Bilbao, Reinosa, Santoña, Laredo y Ribadesella. Junto a lo indicado se comercializaban artículos semielaborados de tenería como becerrillos, algunos de Irlanda, cordobanes de Castilla y de la Montaña, gamuzas de Francia, cueros de Irlanda, ante de Francia para Madrid, de Flandes destinado a Castilla, vaqueta, generalmente de Francia, la más difundida ${ }^{49}$, suela y guadamaciles, correjeles tanto de Irlanda, Inglaterra como de la Montaña que se destinan, entre otros ${ }^{50}$, a la fábrica de Juan de Isla en Marrón ${ }^{51}$, badana y tafilete. En relación con esta industria, simultánemente sale al exterior por Santander, el zumaque del Reino, que se conduce a Londres y Liverpool.

Por su parte los talleres de tinte españoles y otros europeos a través de Burdeos, Bayona, Londres, Amsterdam o Bristol, son los destinatarios de los colorantes procedentes de América que se canalizan por el puerto santanderino. Tal es el caso del palo campeche $e^{52}$, añil ${ }^{53}$, palo brasil, agalla y grana, esta última para Logroño. Entretando, la rubia de Castilla ${ }^{54}$ se desplazaba a Londres, para distintas zonas de Inglaterra, y a Cádiz. Simultáneamente, también se anotan otros productos requeridos en la tinción como los mordientes representados por caparrosa y piedra lumbre de origen extranjero. No obstante, la práctica de diversos tipos de pintura explica la presencia en las cargazones de elementos importados como cardenillo, minio, precipitado blanco y rubio, espíritu nitro, aceite vitriolo, aceite petróleo, almidón, albayalde, oropimente, aceite de linaza, goma arábiga, trementina que tienen como destino preferente Reinosa, Madrid, Burgos, la Real Fábrica de Vidrio y Cristal de San Ildefonso, por lo que al minio se refiere, y La Habana.

\footnotetext{
48 LARRUGA, Eugenio: Memorias políticas y económicas sobre los frutos, comercio, fábricas y minas de España, t.XXXI, p. 356, Fábrica de cueros a la inglesa.

49 Vaqueta llega a La Coruña, Castroponce, Marrón, Ferrol, Reinosa, Simancas, Burgos, Bilbao, Asturias, Madrid, Navia, Ares, Melgar y muy distribuida por vecinos de Villalón, Santander, Herrera de Pisuerga, Benavente, San Pedro, Villarramiel,

so Correjeles se envían a Cádiz, Madrid, Valladolid, Simancas, Cieza, La Coruña, Ferrol, La Nava, Asturias, Reinosa, Peñaranda, Cantalapiedra, Medina, Cádiz, Navia

51 Miguel, Isabel: Op. Cit., 1999, p. 200.

52 Palo campeche se recibe en Bilbao, San Sebastián, Palencia, Valladolid, Cantalapiedra, Lerma, Peñaranda, Madrid, Burgos, Melgar, Segovia, Reinosa, Burdeos, Villada, Bayona, Ruan, Saldaña, Toledo, Salamanca, Holanda, Bilbao,

53 Añil se envía a Burgos, Palencia, Valladolid, San Sebastián, Londres, Amsterdam, Bristol, Roba, Provincias Exentas y Castilla, en alguna ocasión se distribuye por vecinos de Baltanás

54 Originaria de la zona de Portillo en Valladolid y de Cuéllar en Segovia. MiguEL, Isabel: Op. Cit., 1999, p. 54
} 
MAPA VIII: Destinos de los cueros al pelo emitidos desde Santander

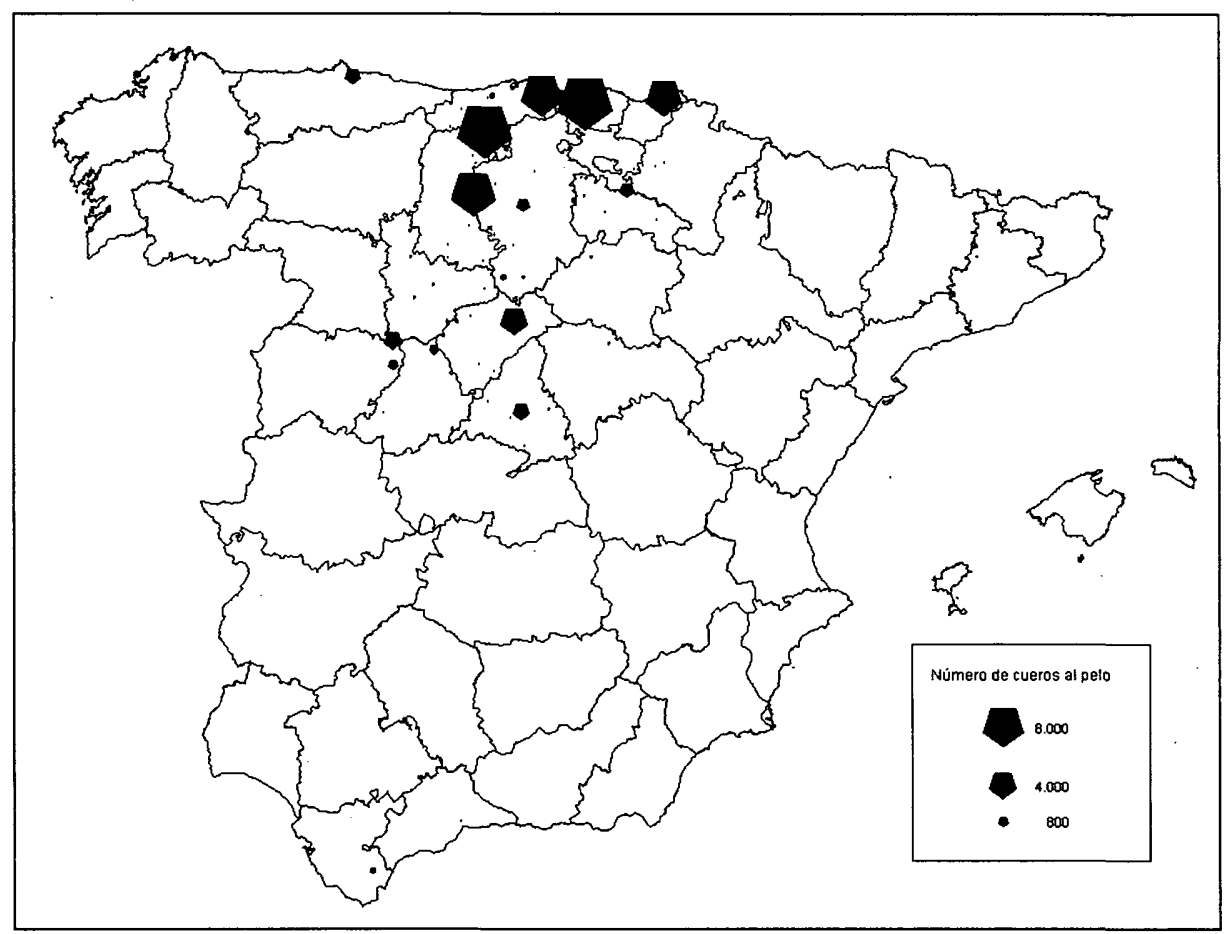

Fuente: Documentación mencionada en nota 4.

Nota: También van a Bayona, Burdeos, Ostende y Londres.

La fabricación de lonas y de los distintos aparejos marineros, exponentes del desarrollo naval de la época, se atestigua con la comercialización de fibras como lino en libretas, en rama, rastrillado, sin rastrillar de Castilla que se destina a los puertos gallegos, al igual que el cáñamo de Aragón, si bien el primero llega también al interior, en concreto a Soria ${ }^{55}$, donde simultáneamente se registran algunas partidas de Holanda, mientras que el cáñamo se recibe asimismo en Madrid y Guadalajara, en tanto que otra fibra importada en alza, el algodón, va a La Habana y es distribuida por el interior de la Cuenca del Duero. Igualmente las necesidades de la actividad naviera motivan el comercio de alquitrán desde Santander a Burdeos, La Habana y numerosos puertos gallegos, así como de brea que, además de los enclaves indicados, se envía a Canarias, al tiempo que la pez se transporta a La Habana y se extraen jarcia y herrajes procedentes de la

ss Miguel, Isabel: Op. Cit., 1999, pp.351-356, en el ámbito de la antigua provincia de Soria se encontraba Cervera del Río Alhama donde se trabajaba con esta fibra, en una industria notable.

Hispania, LXIV/2, núm. 217 (2004) 601-636 
fábrica de Juan de Isla ${ }^{56}$, hacia los ámbitos mencionados anteriormente, en los que también se reciben maderas extranjeras de pino, haya, algunas destinadas a Barcelona, a veces en forma de arcos o duelas que se dirigen a Burdeos, Montevideo, Cádiz y Corcubión donde también se registra mimbre para arcos.

En esta senda de aprovisionamiento para las actividades transformadoras se sitúa la comercialización de hierro, preferentemente originario de la Montaña y de Vizcaya ${ }^{57}$ y también de acero, en ocasiones de Mondragón, de clavazón de Guarnizo para el Canal de Castilla y La Coruña, en este caso destinada a toneleros, de tachuelas e hilo de hierro para la fabricación, entre otros, de cardas, hierros para cepillos y barras del mismo material que atraviesan el Atlántico hacia puertos americanos, al igual que los trompos y quifos montañeses y vizcaínos para los ingenios de azúcar cubanos. Se registran simultáneamente, diversos semielaborados para la transformación metálica, como hojalata, peltre, latón en plancha, así como cobre en pasta, o bien cobre labrado, en alguna ocasión proveniente de Perús ${ }^{8}$ o de Méjico en 1777, sin faltar estaño tanto en barras, como labrado.

Asimismo, la peletería madrileña fue la principal receptora de un cargamento importado muy específico ${ }^{59}$, aunque ciertas pieles se dirigieron también a Alcobendas, San Sebastián, Burgos y Plasencia. Entretanto, la velería requería cera amarilla proveniente de Flandes y de Sevilla, en panes y sin labrar que se transportaba a Sepúlveda, Madrid, Dueñas, Burgos, Bilbao, Madrid y Soria, así como cera blanca a La Coruña.

Original resulta el tráfico comercial de intestinos de vacas para la elaboración de embutidos que tienen como destino casi exclusivo Ledesma, pues sólo alguna partida va a Reinosa, de manera que Santander se convierte en otra vía de entrada de este producto desde Francia, que se remitía también a través de la frontera portuguesa a la citada localidad salmantina ${ }^{60}$, donde, al parecer, un grupo de franceses había instalado un obrador de aquellos.

No sólo materias primas o semielaborados, sino que desde el puerto santanderino se desplazan múltiples elementos empleados en el funcionamiento de diferentes actividades económicas, es decir, podrían considerarse parte del equipamiento de los sectores productivos. Así, la agricultura se aprovisiona de mielgas,

\footnotetext{
56 Miguel, Isabel: Op.cit., 1999, p. 201, Juan de Isla poseía ferrerías en Ampuero y Cereceda. Arroyo Valiente, Pedro, Corbera Millán, Manuel: Ferrerías en Cantabria: Manufacturas de ayer, patrimonio de hoy, Santander, 1993

57 Este hierro se dirigía a Mugía, Camariñas, Canarias, Corcubión, Ribadeo, Ferrol, Puentedeume, Buenos Aires, Reinosa, Marrón, Valladolid, Barcelona, Asturias, San Sebastián, Madrid, Bilbao y Londres.

s8 Cobre que es enviado a Salamanca, Reinosa, Fuentes de Valdepero, La Coruña, y de Valmaseda a Camariñas

59 Madrid es la destinataria de pieles de conejo, de gato, de ardilla, de oso, forros de pellejo de jineta, de castor, de cisne, de tigre,

60 Miguel, Isabel: Op. Cit. 2000, p. 62
} 
guadañas, dalles del Reino que se distribuyen por la Montaña y norte de $\mathrm{Pa}$ lencia, especialmente Olleros y Perazancas, e incluso se desplazan a Cádiz, al igual que azadones de hierro se destinan a Buenos Aires y La Habana. En el mismo sentido, se explica la variedad de instrumental, generalmente europeo, empleado en distintos oficios ${ }^{61}$ que acompaña los cargamentos impulsados desde Santander preferentemente a Burgos, Madrid, Valladolid, El Canal de Castilla y los puertos americanos de La Habana, La Guayra, Buenos Aires y Montevideo.

\section{I.4. Diversos}

A todo lo referido se sumaban numerosos artículos para consumo final. En este sentido se registran en la aduana santanderina con dirección a otros ámbitos artículos de cuero como zapatos fabricados en Santander y los elaborados en Inglaterra ${ }^{62}$. Igualmente se distribuían objetos de vidrio y cristal, en los que se incluyen piezas foráneas de calidad junto a otras de la Real Fábrica de La Gran$\mathrm{ja}^{63}$, así como variadísimos productos de alfarería entre los que, al lado de los hispanos, se encuentran los manufacturados en Holanda e Inglaterra ${ }^{64}$.

Todos ellos se acompañaban de útiles de metales distintos (hierro, latón, hojalata, estaño, bronce, cobre) integrantes del menaje doméstico, ornamental o de escritorio, de factura europea, excepción hecha de algunos de hierro ${ }^{65}$. No obstante, la variedad y número tuvo su paradigma en los centenares de miles de botones registrados, diferentes por su material (estaño, asta, piedras, oro, plata,

61 Leznas para zapateros, alicates, tijeras, limas, navajas de barbero, estuches de compases y plumas, azuelas, cuadrantes, sierras, serrotes, serruchos, gubias, formones, barrenos, martillos, escoplos para carpinteros, aunque también se anotan lancetas, tenazas, machetes, hachas y palas de hierro de Guipúzcoa, bocados del mismo metal y cortadores de acero, cuchillos para los zurradores de Melgar, plataformas, piezas y piñones de reloj para relojeros y bigornias de platero,

62 Otros artículos de cuero eran botas de becerrillo, a veces de Inglaterra, guantes de gamuza, sillas y guarniciones de caballo, así como pellejos de vino.

63 Los objetos de vidrio, mayoritariamente extranjeros, son vasos o copas, frascos diversos para «agua de olor» y para polvos, espejos, incluso de faltriquera, cornucopias, saleros, vinagreras, botellas extranjeras y de Castilla, fanales, faroles de cristal y de faltriquera, obras de cristal, láminas pintadas en vidrio, anteojos de teatro, para leer y de larga vista, de suelo, así como vidrios de aumento.

64 Se trata de aguamaniles, palanganas, jarras, cazuelas, saleros, fuentes, platos, escudillas, tazas, jícaras de Holanda, todo tipo de vajilla, loza de china, de Inglaterra, crisoles de barro, orinales y tiestos.

65 De bierro se presentaban escopetas de Vizcaya, navajas, almireces, eslabones, llaves de reloj, cerrajitas y candados, tenazas, bruzas para limpiar caballos, ollas, quincalla, hebillas, ganchos, cuchillos, charreteras, balanza, aldabillas con aleación de latón, tenedores, campanillas, alfileres, agujas de coser y de calceta, juegos de morillos, espadines y cadenas de acero. En latón se anotaban dedales de París, jeringas, hebillas y candeleros, compases, mientras de estaño se transportaban platos, fuentes, tarteras, cucharas, tenedores, teteras, tinteros, dedales, candeleros, tabaqueras, corchetes, cortaplumas, despabiladeras, cerrajas, candados, tinteros de faltriquera, hebillas, palanganas con mezcla de latón, así como azafates y bandejas de bojalata, visagras de bronce y cacerolas de cobre.

Hispania, LXIV/2, núm. 217 (2004) 601-636 
vidrio, similor, cascarilla, nácar, madera) y por su destino en la prenda (chupa, casaca, chaleco, puño de camisa o botines), mayoritariamente extranjeros, salvo unos botones de hilo de Asturias.

La complejidad del ajuar doméstico se vio completada por muebles de madera, instrumentos de música, juguetes o cajas importados ${ }^{66}$, al lado de escobas de palma de Andalucía. Asimismo, la belleza y el aseo se satisfacen con la comercialización a través de Santander de variados productos ${ }^{67}$ y sobre todo de jabón de Francia, de Marsella, con gran dispersión geográfica en su desplazamiento ${ }^{68}$. No están ausentes los artículos de procedencia europea orientados al adorno personal o suntuario ${ }^{69}$, ni tampoco faltaron los elementos de farmacopea de origen extranjero ${ }^{70}$, indicadores de un activo desarrollo de la misma. Entretanto, los indicios del mundo del saber se encuentran representados mediante libros de cirugía y religiosos ${ }^{71}$, mapas o estampas procedentes de Francia.

Esta multitud de objetos de consumo final, útiles o suntuarios, nuevos o tradicionales, originarios, fundamentalmente del exterior, tuvieron como destinos más frecuentes los puertos asturianos y gallegos, como vía de entrada a sus respectivos territorios, Bilbao, Madrid, Valladolid, Burgos, Palencia, Reinosa, Canarias y los puertos americanos, además de algunos europeos como Bayona o Burdeos. No obstante, los objetos de alfarería ofrecieron mayor inclinación por la Montaña y Castilla, mientras los artículos de metal se decantaron por $\mathrm{La}$

66 Se trataba de cunas de mimbre, catres y colchones, cama de palo, sillas de madera y de paja, algunas originarias de Holanda, mesas de pino, tocador de caoba, armarios, papeleras y cajas de nogal, cómodas, fuelles de cocina, brasero, estufas, violones, flautas de madera, piano forte, cascabeles, alfiliteros de palo y hueso, molino de pimienta, trompas de caza, cajas de jaspe y de cartón para tabaco, cuerno de ciervo y diversos tipos de velas, algunas procedentes de Inglaterra, cubos para agua,

67 Polvos para pelucas y para limpiar los dientes, hojas de talco, carmín, cepillos para ropa y para los dientes, peines de boj o de hueso de Francia, laca, agua de olor, agua de la reina de Hungría y plumas.

68 El jabón se destinaba, sobre todo, a Mugía, Camariñas, Corcubión, Villaviciosa, Potes, Aguilar, San Andrés del Arroyo, Ferrol, Manzanares, San Vicente de la Barquera, Sigüenza, Canarias, Laredo, Limpias, Madrid, Reinosa, Mular, La Habana, «Galicia», Limpias, Camariñas, Laredo, Corcubión, Puerto Vega, Astorga

69 Se registraban pendientes, sortijas de diamantes, de metal con piedras preciosas, cruces de latón, collares de canutillo y de perlas, topacios orientales, madreperlas, granates, esmeraldas, zafiros, anillos, abalorios de vidrio, medallitas de metal, aderezos de broches, arracadas y lazos, rosarios de hueso, charreteras y trenzas de oro y plata, plata labrada y cordones para reloj, gargantillas de cera, pipas de yeso, bastones con puños de oro, de pino, de caña, abanicos, cartera bordada en plata, presillas de plata, estuches de sortijas, relojes de plata de faltriquera, de sala, despertador, de sobremesa con caja de caoba y remates de bronce y escribanía de plata.

70 Los principios más frecuentes eran las hojas de sen, alcanfor, acíbar, cantáridas, flor de lúpulo, mirra, incienso, santónico, bálsamo de Copaiba, tamarindo, tucia, tierra sellada, sándalo, bejuquillo, uñas de la gran bestia, uñas de cangrejo, gutagamba, piedra lazulí, piedra vervar, "curafístulas», expilcarética, litargirio, ruibarbo, purga de Jalapa, víboras secas, goma de palo de santo, valitodo, arsénico, sagupelo, sal bolutil de víboras, sal de saturno, popolaco, cascarilla, almástiga, almidón, raíz de butua y útiles sanitarios como jeringas

71 Algunos de los títulos eran Gritos del Purgatorio, Misa del Cid, Viajes de Jerusalén.

Hispania, LXIV/2, núm. 217 (2004) 601-636 
Habana, la farmacopea por Madrid y Burgos y la joyería por Burgos, Valladolid, Madrid y La Habana.

\section{II. ¿QUIÉNES PARTICIPAN?}

La aproximación a la variedad de productos, su posición relativa y destino debe completarse con el perfil de quienes actuaron en este comercio, ya fuera como comerciantes al por mayor, ya como transportistas y agentes de comercialización o consumidores finales, por cuanto fueron los artífices de su desarrollo durante el periodo, contribuyendo a la expansión del puerto montañés y a la configuración de su ámbito de influencia.

Las identidades registradas en la documentación utilizada nos permiten delimitar el grupo de los comerciantes más destacados que actúan en relación con este tráfico comercial. Entre los santanderinos emisores son recurrentes todos los años de la serie analizada Antonio Callejo, José Antonio del Mazo y, quien será su yerno y apoderado general de su comercio, Antonio del $\mathrm{Campo}^{72}$, a ellos se suman otros muchos que varían a lo largo del tiempo y aumentan su número en los años ochenta (Cuadro IV). Estos hombres son el exponente del paulatino interés por el comercio en la ciudad cántabra ante las expectativas generadas por la actividad con el aliciente americano, no en vano algunos de ellos tejieron sus negocios en la Carrera de Indias con navíos, azúcar, cacao y harina, animaron el Consulado santanderino ${ }^{73}$, la Real Sociedad Cantábrica ${ }^{74}$ y la vida de la ciudad. Es precisamente en la década de los ochenta cuando se percibe también la presencia de los comerciantes bilbainos que giran desde Santander, cual es el caso de "Gardoqui e hijos», firma relevante vinculada a las transacciones hispanoamericanas y a la Corte ${ }^{75}$. Por su parte, los comerciantes receptores de las mercancías emitidas desde el puerto montañés, que han podido ser reconocidos, han sido Juan Antonio de Ibarguengoitia de Bilbao, habitual en el tráfico americano, al igual que Diego Echagüe de San Sebastián, relacionado con la Compañía de Caracas $^{76}$, Jerónimo Hinojosa y Ramón Fernández en La Coruña. Entretanto, en Reinosa eran habituales Tomás Villegas, Bernardo Cámara y Blas Martínez. Al sur de la cordillera Cantábrica, son los comerciantes de Madrid, Valladolid y sobre todo de Burgos, los más reiterados

72 Miguel, Isabel: Op. Cit. 1992, p. 257, Antonio del Campo, comerciante, armador e industrial cervecero de Santander y futuro conde de Campogiro.

73 Miguel, Isabel: Op. Cit. 1992, p. 145, 276

74 Demerson, Paula: Próspera y adversa fortuna de la Real Sociedad Cantábrica. 1775-1804, Santander, 1986

75 Sobre esta sociedad RUEDA, Natalia: La Compañia comercial «Gardoqui e Hijos». 1760-1800, Vitoria, 1992. ZABALA, Aingeru: Mundo urbano y actividad mercantil. Bilbao 1700-1810, Bilbao, 1994, pp. 606--647

76 Miguel, Isabel: Op. Cit. 1992, p. 258

Hispania, LXIV/2, núm. 217 (2004) 601-636 
como destinatarios (Cuadro V), si bien se registra también la actividad de Manuel Antonio de Igea de Soria ${ }^{77}$, de Sebastián Pastor Gómez en Palencia, de José de Silva en Ledesma y de Vicente Ocampo en Salamanca, entre otros.

\section{CUADRO IV: Principales comerciantes santanderinos} identificados en las transacciones analizadas

$\begin{array}{llll}\text { Antonio Callejo } & \text { Felipe Aguirre } & \text { Ramón Viàl } & \text { José Escalante } \\ \text { Juan Victorica } & \text { Bernardo Reigadas } & \text { Andrés Nougaro } & \text { Felipe Aguirre } \\ \text { José del Mazo } & \text { Juan Aguirre } & \text { Juan González de Arce } & \text { Nicolás Forcade } \\ \text { Nicolás Vial } & \text { Juan Barangot } & \text { Ramón López Dóriga } & \text { Francisco del Castillo } \\ \text { Luis Collantes } & \text { Francisco Gibaja } & \text { Antonio Gordey } & \text { Manuel Díaz de Cossío } \\ \text { Francisco Bolantín } & \text { Matías Heras Soto } & \text { Manuel Senties } & \text { Blas Martínez } \\ \text { Juan Hill } & \text { José Pedrueca } & \text { Antonio del Campo } & \text { José Fausto Vildosola } \\ \text { Juan Laplace } & \text { Juan Antonio Gutiérrez } & \text { Pedro de la Sota } & \text { Juan Laut }\end{array}$

Fuente: Documentación mencionada en nota 4.

CUADRO V: Algunos comerciantes destinatarios identificados en este comercio

\begin{tabular}{|c|c|}
\hline \multicolumn{2}{|l|}{ BURGOS } \\
\hline $\begin{array}{l}\text { Antonio Domínguez de } \\
\text { la Torre }\end{array}$ & $\begin{array}{l}\text { Manuel García } \\
\text { Oyuelos }\end{array}$ \\
\hline $\begin{array}{l}\text { Casimiro Domínguez } \\
\text { de la Torre }\end{array}$ & $\begin{array}{l}\text { Diego de la Puente } \\
\text { Morales }\end{array}$ \\
\hline $\begin{array}{l}\text { Tomás Martínez } \\
\text { Velasco }\end{array}$ & Antonio Tomé \\
\hline Mendieta y Cía & Paula de la Puente \\
\hline Agustín Castillo & José Ramón Igarza \\
\hline Victor de Casas & Juan José Isla \\
\hline Paula de la Puente & $\begin{array}{l}\text { Francisco de la } \\
\text { Infanta }\end{array}$ \\
\hline Atienza y Cía & Gaspar Herrera \\
\hline
\end{tabular}

VALLADOLID
Luis Pérez Infante
Francisco Buisam
Juan Bautista Razeto
Pedro Jover
Juan González
Pedro Orduña
Juan Cidrón

MADRID

Zulueta y Cía

Jerónimo Cobobriz

Juan Ignacio Goyeneche

Simón Pérez

Juan Antonio de la Torre Sixto García de la Prada Ramón Sierra

Fuente: Documentación mencionada en nota 4.

Si numerosos son los comerciantes anotados, resultan centenares los transportistas movilizados en los intercambios revisados, sin cuya actividad este comercio hubiera sido incompleto, puesto que se convirtieron en los difusores de productos, diseñando el alcance geográfico del impulso santanderino y de su capacidad de atraccción. Predominan los originarios de los alrededores de San-

77 Miguet, Isabel: Op. Cit. 2000, pp. 130-131, se recoge alguna información sobre este comerciante y su hijo 
tander, Alto Campoo, Campoo de Yuso y de diversos núcleos de Palencia, Valladolid y Burgos, sobresaliendo en esta última, la localidad de Escalada y su entorno, donde la familia Gallo, que sugiere una empresa de transportistas, ofrece una presencia permanente. La localización cartográfica de su vecindad proporciona el diseño de un vector Santander-Valladolid de elevada concentración, a partir del cual la densidad se atenúa hacia el exterior del espacio definido, que abarca, preferentemente, el ámbito de la actual región de Castilla y León y de la Rioja, con localizaciones más alejadas ubicadas en Aragón, Madrid o Castilla meridional (Mapa IX).

MAPA IX: Vecindad de los transportistas relacionados con el comercio generado en torno a Santander (1766-1785)

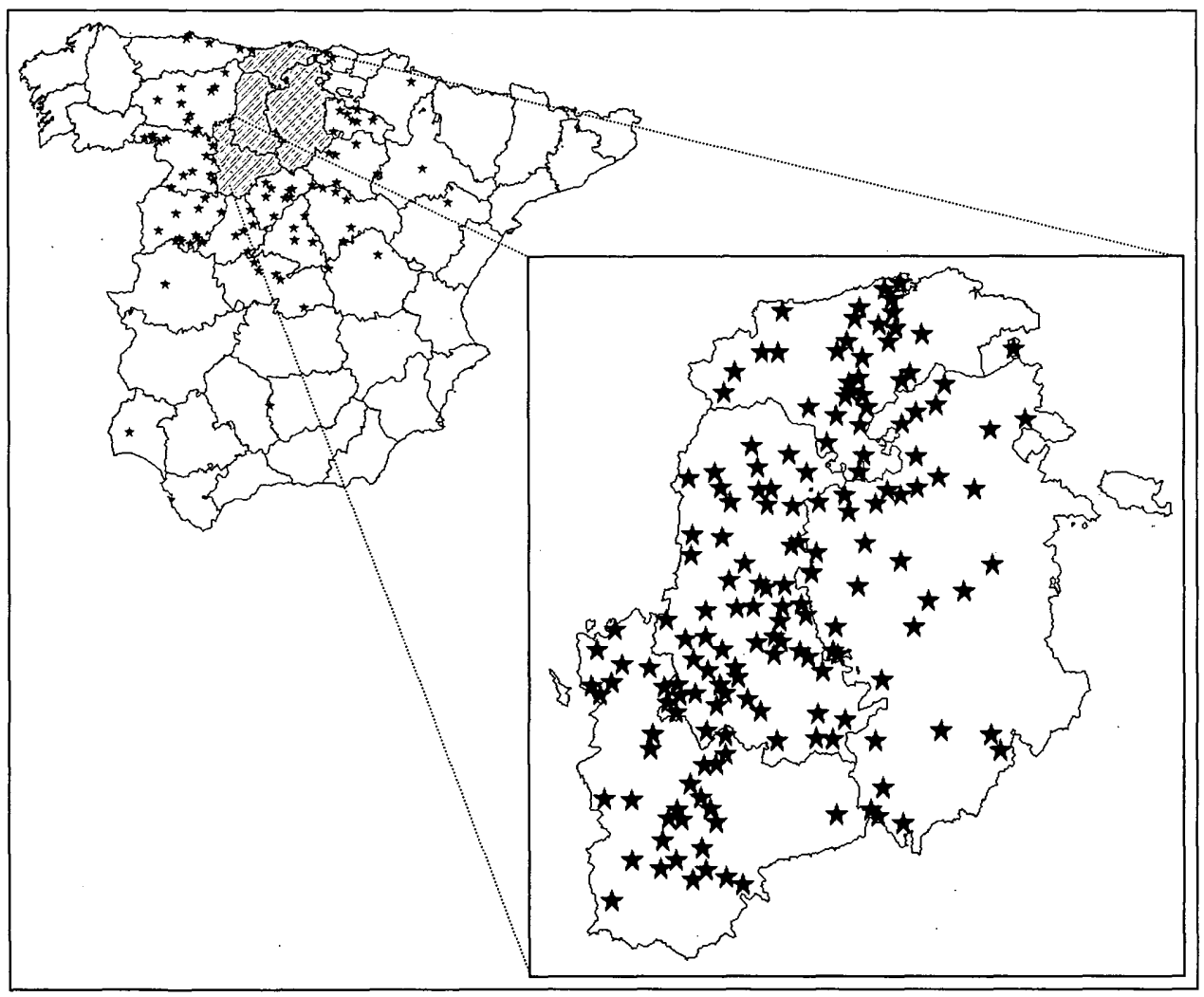

Fuente: Documentación mencionada en nota 4. 
En cuanto a los destinatarios finales especificados, hay que mencionar los monasterios y conventos de los ámbitos santanderino, madrileño, vallisoletano, palentino y burgalés (Anexo I). Junto a ellos son habituales los Hospitales Reales y el Abasto de Madrid, los destacamentos del Ejército en La Coruña y Ferrol, las fábricas de curtidos de Diego Tomé en Melgar de Fernamental y de Juan de Isla en Marrón, así como las instalaciones y fábricas del Canal de Castilla y los obradores de Madrid. Igualmente se registran algunos nobles en diversas ciudades, embajadores y nuncios en la capital del Reino. Sin embargo, más significativa resulta la presencia de múltiples personas de las áreas geográficas indicadas en los distintos mapas, cuya identidad, aunque vinculada a una localidad, no es posible, por el momento, relacionarla con una dedicación, posición social o institución específica, a fin de precisar su conocimiento y que, no obstante, son el testimonio de una realidad económica en la que el comercio de larga distancia es más que una anécdota, al involucrar a numerosos individuos y ofrecerles, entre otras, aquellas mercancías cuyo efecto demostración va modificando, aunque sea lentamente, las pautas de consumo de la sociedad de la época.

\section{SANTANDER: ARTICULADOR Y REDISTRIBUIDOR}

Al hacer balance de la información proporcionada por la documentación estudiada, se constata que ésta ha permitido definir la composición, los agentes y las principales directrices de los intercambios generados en torno a Santander en una etapa anterior a la de su apogeo comercial dieciochesco, aquella que abarca desde su habilitación para el comercio con las islas de Barlovento hasta la confirmación de su posición en el Cantábrico, desligándose de Burgos y erigiendo su propio Consulado. Estas referencias son tanto más importantes cuanto que es, en este periodo, cuando tiene lugar la definición de algunas pautas de su trayectoria posterior, constituyentes de su singularidad.

En efecto, Santander se convierte durante estos años con rapidez, al amparo de la Corona, en el articulador, desde el Cantábrico, de un amplio espacio que conecta el occidente de Europa, mediante los puertos franceses del Atlántico (Burdeos, Bayona), Bristol, Londres y Amsterdam ${ }^{78}$, con la mitad norte de España, tanto interior como litoral y América, en concreto Cuba, Nueva España y Río de la Plata. Proceso que se desarrolla a lo largo de un periodo que se inscribe en una onda expansiva del comercio septentrional hispano y atlántico en general $^{79}$, coincidiendo con la etapa en la que Bilbao, hasta entonces el gran

78 ZaBALA, Aingeru: Op. Cit., 1983, t.II, pp. 94, 141-142, 194, 206-208, 233

79 BUTEL, Paul: Les negociants bordelais, IEurope et les Iles au XVIIIème siècle, París, 1996, pp. 17, 381-382, 391-392 IBIDEM: Européens et espaces maritimes (vers 1690-vers 1790), Bordeaux, 1997, p. 77, se constata cómo el puerto de Burdeos experimenta su crecimiento más rápido precisamente entre 1767 y 1792, ejerciendo de salida al vino y productos de Aquitania, mientras tiene cada vez más importancia en su actividad el componente colonial y se intensifica su relación con la España cantábrica.

Hispania, LXIV/2, núm. 217 (2004) 601-636 
núcleo portuario del Norte, enlace con Europa, comienza a tener dificultades ${ }^{80}$, mientras La Coruña, puerto de Correos Marítimos con América ve atenuada su expansión desde $1778^{81}$ y Gijón, habilitado para el comercio con las Indias, no logra despegar en ese rumbo ${ }^{82}$. En este sentido, los datos de aduanas ${ }^{83}$ confirman que el tramo temporal estudiado corresponde al de la alteración de posiciones entre los puertos cantábricos mencionados, de modo que el puerto cántabro presenta el crecimiento relativo más importante, sobre todo entre 1768 y 1778 , intensifica su relación con América y, ya terminada la guerra de Independencia de Estados Unidos, fortalece su posición en el conjunto del comercio. Precisamente es en la vertiente americana en la que Santander termina también por superar a La Coruña en el valor global de las exportaciones a Indias, al situarse tras Cádiz, Barcelona y Málaga ${ }^{84}$, convirtiéndose, en fin, en el puerto del Cantábrico más dinámico, a pesar de su punto de partida mínimo, en competencia con Bilbao que no dispone del horizonte indiano. Una muestra de la importancia del factor ultramarino es la información del Administrador de la Aduana santanderina, según la cual, entre 1766 y 1785, los ingresos proporcionados por el Comercio Libre superan, por término medio, el 35 por ciento de los ingresos globales, alcanzando en 1785 el 51 por ciento ${ }^{85}$. En consecuencia, Santander no sólo diseña en estos años las conexiones entre los espacios indicados, sino que lo hace introduciendo los elementos que contribuyen a la transformación que experimentan los puertos de la España cantábrica respecto a sus funciones e intensidad de actividad ${ }^{86} \mathrm{y}$ de la que él sale favorecido, al aprovechar la oportunidad.

Paralelamente se decanta como núcleo redistribuidor, preferentemente, de productos externos, ya sean coloniales (azúcar, cacao, cueros al pelo) hacia la mitad norte de España y la Europa atlántica, y de bacalao y tejidos extranjeros de lino, lana y algodón hacia el mismo ámbito hispano y con destino a los terri-

80 ZABALA, Aingeru: Op. Cit. 1994, pp. 287-320

81 AlONSO, Luis: Op. Cit. 1987, p. 172, ZaBAlA, Aingeru: Op. Cit., 1983, t.II, p.310

82 PERIBÁNEZ, Daniel: Comunicaciones y comercio marítimo en la Asturias preindustrial. 1750-1850, Gijón, 1992. MiGUEL, Isabel: Op. Cit. 1992, pp. 279-289

83 ZABALA, Aingeru: «La distribución de la actividad comercial en el Cantábrico en torno a los decretos de Libre Comercio» en Mercado y desarrollo económico en la España Contemporánea, Madrid, 1986, pp. 44-56

84 FISHER, John: «Imperial «Free Trade» and the Hispanic Economy, 1778-1796» en Journal of Latin American Studies (Cambridge) 13, part 1, (1981), p. 42

85 Miguel, Isabel: Op. Cit. 1992, pp. 238-239. El Administrador de la Aduana santanderina, Diego Tricio Nájera, da cuenta de los ingresos aduaneros correspondientes al periodo 1766-1785, tanto de los globales como de los del Comercio Libre.

86 ZABALA, Aingeru: Op. Cit. 1994, p. 341. Indica el autor que el negocio comercial de Asturias se estanca, el de Bilbao es estable lo que significa pérdida de peso específico porque el conjunto del comercio del norte crece, aumenta La Coruña y mucho más Santander. IBIDEM: Op. Cit., 1983 , t. II, pp. 302-303, expresa que la recaudación de los niveles de diezmos pasa de 483.000 reales de vellón en 1752 a 3 millones y medio en el quinquenio 1752-1757, hasta los 13 millones de reales de vellón del periodo 1772-1778. 
torios americanos, sobre todo Cuba. De manera que en este periodo, la función de canalizador de la producción montañesa y de otras mercancías del Reino (rubia, zumaque, cereales, harina, tejidos de lana, estampados, hierro, lino, cáñamo, vidrio) hacia los ámbitos exteriores definidos es muy reducida. Esta estructura de la redistribución indica que, durante las dos décadas anteriores al comienzo del auge comercial harinero con América, Santander había definido su función merced al azúcar y cacao americanos por un lado y al bacalao y los tejidos extranjeros por otro, es decir, al margen de la producción cántabra y de las tierras inmediatas. Comportamiento diferente al del puerto de La Coruña que hasta los años ochenta había contribuido a dar salida a los lienzos gallegos ${ }^{87}$, del barcelonés, en el momento de su apogeo comercial, que canalizó la producción catalana ${ }^{88}$, del malagueño que hizo lo propio con las pasas y el vino de la tierra ${ }^{89}$ o del mallorquín por el que se extrajo, sobre todo, el aceite y el aguardiente de la isla ${ }^{90}$.

Simultáneamente, la cartografía de la redistribución de las mercancías en la Península muestra claramente los vínculos territoriales preferentes del puerto santanderino que se han ido reflejando a lo largo del estudio. Así, se constata una articulación intensa con las tierras del valle del Duero, en torno al eje del Camino de Reinosa y sus aledaños. En ella se involucran zonas que movilizan transportistas de un mundo rural que encuentra en este tráfico la alternativa para salir de la precariedad económica o para diversificar y ampliar sus ingresos ${ }^{91}$. A esta conexión interior se suma la relación marítima, de cabotaje, con Galicia, Asturias y en especial con el País Vasco, al iniciarse en este momento un deslizamiento de los intereses comerciales de bilbainos y donostiarras al puerto santanderino, tras la no habilitación de los puertos de las Provincias Exentas para el comercio con

87 Alonso, Luis: Op. Cit., 1987, p. 166. MeIjIDE, Antonio: Op. Cit., 1984

88 GARCÍA-BAQUERO, Antonio: "Comercio colonial y producción industrial en Cataluña a fines del siglo XVIII» en Agricultura, comercio colonial y crecimiento económico en la España Contemporánea, Barcelona, 1974, p. 272. DelGADO, José María: «El puerto de Barcelona en la época preindustrial» en Economía e Historia del puerto de Barcelona, Madrid, 1992, pp. 17-80. MARTínez SHAw, Carlos: Cataluña en la Carrera de Indias, Barcelona, 1981. MARTínEZ SHAw, Carlos: "Cataluña en el Siglo XVIII bajo el signo de la expansión» en España en el Siglo XVIII, Barcelona, 1985, pp. 93-95. OLIVA, José María: «Reflexiones en torno al Comercio Libre de Barlovento: el caso catalán» en Comercio Libre entre España y América Latina, 1765-1824, Madrid, 1987, pp. 71-94.

89 GÁmEZ, Aurora: «Aproximación a la influencia del Libre Comercio con América en la Economía de Andalucía Oriental» en Comercio Libre entre España y América Latina, 1765-1824, Madrid, 1987 , pp. $127-128$

90 MANERA, Carlos: «Producción agraria e infraestructura mercantil en el comercio mallorquín con América, 1778-1818" en Comercio Libre entre España y América Latina, 1765-1824, Madrid, 1987, pp. 235-237. IBIDEM: Comerş $i$ capital mercantil a Mallorca, 1720-1800, - Palma de Mallorca, 1988, pp. 230-235. IBIDEM: Historia del creixement economic a Mallorca (1700-2000), Palma de Mallorca, 2001, pp. 96-97

91 RiNGROSE, David: Los transporte y el estancamiento económico de España (1750-1850), Madrid, 1972. MADRAZO, Santos: El sistema de transportes en España, 1750-1850, Madrid, 1984 
América. Exponente de este vínculo económico con el País Vasco lo representaría el hecho de que Bilbao y San Sebastián son los dos núcleos, entre otros, para los que con mayor asiduidad y cuantía se registra el flujo de dinero en la documentación analizada, sólo superados por Reinosa en $1785^{92}$.

En definitiva, la consolidación como redistribuidor euroamericano se manifiesta en la formación de un grupo cada vez más nutrido de comerciantes, que tejen sus redes de negocios conectando especialmente, a través del puerto montañés, los núcleos urbanos de Palencia, Valladolid, Burgos, Madrid, Bilbao y San Sebastián ${ }^{93}$, con el oeste europeo y sobre todo con Cuba. Estas redes comerciales tienen el estímulo americano y acercan a la sociedad numerosos productos, proyectando su incidencia en las pautas de consumo, pero también abriendo las expectativas de un mercado susceptible de ser aprovechado por los sectores productivos del Reino, al convertirse el puerto santanderino en canalizador de recursos obtenidos en espacios económicos más alejados, bien sea la Cuenca del Duero por razones geográficas y de infraestructuras viarias o del País Vasco por razones de política comercial y fiscal, en relación con América. Se asiste, pues, a la configuración de un potencial espacio económico complejo y amplio que estimulado por el impulso indiano tiene su engranaje en Santander.

\section{BIBLIOGRAFÍA}

Alonso Alvarez, L: Comercio colonial y crisis del Antiguo Régimen en Galicia, 1778-1818, Santiago, 1986.

: «Comercio gallego entre 1764 y 1820 . Estado de la Cuestión» en Comercio Libre entre España y América Latina, 1765-1824, Madrid, 1987, pp. 165-182.

ARroyo VAliente, P. y Corbera Millán, M: Ferrerías en Cantabria: Manufacturas de ayer, patrimonio de boy, Santander, 1993.

BARREDA, F: Comercio marítimo entre Estados Unidos y Santander (1778-1829), CEM, Santander, 1950.

92 En 1785 Reinosa recibió 1.707 .800 reales de vellón. Los flujos de dinero a las dos ciudades de las Provincias Exentas fueron los siguientes, en reales de vellón, y además se añade en cursiva el que llegó en pesos fuertes: (1766 se refiere a dos meses)

\begin{tabular}{|l|c|c|c|c|c|c|c|c|c|c|c|}
\hline & 1766 & 1767 & 1770 & 1773 & 1774 & 1775 & 1777 & 1780 & 1782 & 1784 & 1785 \\
\hline \multirow{2}{*}{ BILBAO } & - & 335.845 & 976.426 & 698.112 & 564.997 & 524.771 & 278.879 & 618.470 & 221.257 & 598.898 & 853.722 \\
\cline { 2 - 11 } & - & - & 3.800 & 16.270 & 1.625 & 20.890 & 850 & - & - & - & - \\
\hline $\begin{array}{l}\text { SAN } \\
\begin{array}{l}\text { SEBAS- } \\
\text { TIÁN }\end{array}\end{array}$ & 19.000 & 154.000 & 104.217 & 229.857 & 511.064 & 416.558 & 568.604 & 774.630 & 139.526 & 276.466 & 341.558 \\
\cline { 2 - 11 } & - & 300 & - & 1.000 & 1.465 & 3.860 & 1.360 & - & - & - & - \\
\hline
\end{tabular}

93 RiNGROSE, David: España, 1700-1900, el mito del fracaso, Madrid, 1996, p. 312, para un periodo un poco posterior, con ciertos matices se exponen algunos de los vínculos de la red urbana aquí planteados.

Hispania, LXIV/2, núm. 217 (2004) 601-636 
«El engrandecimiento de la ciudad y el Real Consulado santanderino» en Revista Altamira, (Santander) (1955) pp. 243-287.

-: «Prosperidad y desarrollo industrial en el siglo XVIII» en Aportación al estudio económico de la Montaña, Banco de Santander, Santander, 1957, pp. 481-612.

BERNARDOS SANZ, J.U.: «El abastecimiento y consumo de pescado en Madrid durante el Antiguo Régimen», Congreso de Historia Económica, Zaragoza, 2001.

BUTEL, P.: Les negociants bordelais, l'Europe et les Iles au XVIIIème siècle, París, 1996.

: Européens et espaces maritimes (vers 1690-vers 1790), Bordeaux, 1997.

CABARGA, J.S. Santander. Sidón Ibera, Ediciones Estudio, Santander, 1979.

Cubillo De la Puente, R.: El pescado en la alimentación de Castilla y León durante los siglos XVIII y XIX, Universidad de León, León, 1998. 2000.

DelGADO, J.M.: «El puerto de Barcelona en la época preindustrial» en Economía e Historia del puerto de Barcelona, Civitas, Madrid, 1992, pp. 17-80.

Demerson, P.: Próspera y adversa fortuna de la Real Sociedad Cantábrica. 1775-1804, Institución Cultural de Cantabria, Santander, 1986.

DOMÍNGUEZ MARTín, R.: «Política económica y crecimiento urbano-comercial. Santander en la época de Carlos III» en Actas del Congreso Internacional sobre Carlos III y la Ilustración, T. II, Economía y sociedad, Madrid, 1989, pp. 465-491

FISHER, J: «Imperial «Free Trade» and the Hispanic Economy, 1778-1796» en Journal of Latin American Studies, vol.13, part 1, Cambridge University Press, (1981), pp. 21-58.

GÁMEZ, A: «Aproximación a la influencia del Libre Comercio con América en la Economía de Andalucía Oriental», Comercio Libre entre España y América Latina, 1765-1824, Madrid, 1987, pp. 123-143.

GÁRATe, M.: La Real Compañía Guipuzcoana de Caracas, Sociedad Guipuzcoana de Ediciones y Publicaciones, San Sebastián, 1990.

GARCÍA BAQUERO, A «Comercio colonial y producción industrial en Cataluña a fines del siglo XVIII" en Agricultura, comercio colonial y crecimiento económico en la España Contemporánea, Ariel, Barcelona, 1974, pp. 269-294.

Cádiz y el Atlántico (1717-1778). El comercio español bajo el monopolio gaditano, E.E.H.A, Sevilla, 1976.

LARRUGA, E.: Memorias políticas y económicas sobre los frutos, comercio, fábricas y minas de Espa$\tilde{n} a$, Edición facsímil del Instituto Fernando el Católico, Zaragoza.

MADRAZO, S.: El sistema de transportes en España, 1750-1850, Eds. C.I.C.C.P.- Turner, Madrid, 1984.

MAISO GONZÁLEZ, J: La difícil modernización de Cantabria en el siglo XVIII: Don Juan Francisco de Isla y Alvear, Estudio, Santander, 1990.

Hispania, LXIV/2, núm. 217 (2004) 601-636 
MANERA, C.: «Producción agraria e infraestructura mercantil en el comercio mallorquín con América, 1778-1818» en Comercio Libre entre España y América Latina, 1765-1824, Madrid, 1987, pp. 233-248.

Comers $i$ capital mercantil a Mallorca, 1720-1800, Consell Insular de Mallorca Palma de Mallorca, 1988.

: Historia del creixement economic a Mallorca (1700-2000), Lleonard Muntaner, ed., Palma de Mallorca, 2001.

MARTíNEZ BARREIRO, E.: La Coruña y el comercio colonial gallego en el siglo XVIII, Ed. De Castro, La Coruña, 1981.

MARTÍNEZ GUITIÁN, C.): La villa y ciudad de Santander en el siglo XVIII, Madrid, 1950.

MARTínez SHAw, C.: Cataluña en la Carrera de Indias, Crítica, Barcelona, 1981.

: «Cataluña en el Siglo XVIII bajo el signo de la expansión» en España en el Siglo XVIII, Crítica, Barcelona, 1985, pp. 55-131.

MARTÍNEZ VARA T.: Santander de villa a ciudad. Un siglo de esplendor y crisis, Estudio, Santander, 1983.

«Santander y el comercio colonial» en Comercio Libre entre España y América Latina, 1765-1824, Madrid, 1987, pp.183-197.

MARURI, R.: La burguesía mercantil santanderina. 1700-1850: Cambio social y de mentalidad.Universidad de Cantabria, Santander, 1990.

:La burguesía de Cantabria en el siglo XVIII» en La Burguesía española en la Edad Moderna,- Secretariado de Publicaciones de la Universidad de Valladolid, Valladolid, 1996, tomo III, pp. 1287-1322.

MAZA SOLANO, T.: Relaciones históricas, geográficas y económicas de la provincia de Santander en el siglo XVIII, Santander, 1970.

MeijIDE, A.: El puerto de La Coruña en el siglo XVIII, La Voz de Galicia, La Coruña, 1984.

MigUel LóPEZ, I: «Presencia palentina en el comercio hispanoamericano» en Publicaciones de la Institución Tello Tellez de Meneses, (Palencia) 61 (1990), pp. 237-254.

«Pretensión y realidad de la incidencia en Castilla del comercio de Santander con América a finales del siglo XVIII» en Castilla y León en América, Caja España, Valladôlid, 1991.

El comercio bispanoamericano a través de Gijón, Santander y Pasajes, Universidad de Valladolid, Valladolid, 1992.

: «Comercio de Castilla y León con América a través de los puertos cantábricos, 1786-1818» en Cuadernos de Economía de Castilla y León, Servicio de Estudios de la Consejería de Economía y Hacienda, (Valladolid) 2 (1992), pp.157-187.

: «Productos del Reino de Granada en las cargazones cantábricas rumbo a América (1778-1818)» en El Reino de Granada y el Nuevo Müdo, Diputación Provincial de Granada, Granada, 1994, Vol. 1, pp.409-419.

Hispania, LXIV/2, núm. 217 (2004) 601-636 
Perspicaz mirada sobre la industria del Reino. El Censo de Manufacturas de 1784, Universidad de Valladolid, Valladolid, 1999.

: El comercio de Castilla y León al final del Antiguo Régimen, Valladolid, 2000.

MOLAs, P: «La restauración del Consulado de Burgos en el siglo XVIII» en Actas del Congreso de Historia de Burgos, Junta de Castilla y León, Burgos, 1985, pp. 429-440.

MORENO, J: «La producción de harinas en Castilla la Vieja» en Revista de Historia Económica, (Madrid) 2 .(1995), pp. 228-250.

OurvA, J.M.: «Reflexiones en torno al Comercio Libre de Barlovento: el caso catalán» en Comercio Libre entre España y América Latina, 1765-1824, Madrid, 1987, pp. 71-94.

PALACIO ATARD, V.: El comercio de Castilla y el puerto de Santander en el siglo XVIII, Valladolid, 1960.

PERIBÁÑEZ, D.: Comunicaciones y comercio marítimo en la Asturias preindustrial, 1750-1850, Gijón, 1992.

POZUeTA, J. Et alt.: Santander, el puerto y su bistoria. Bicentenerario del Consulado del Mar, Junta del Puerto, Santander, 1985.

RINGROSE, D.R.: Los transporte y el estancamiento económico de España (1750-1850), Tecnos, Madrid, 1972.

España, 1700-1900, el mito del fracaso, Alianza, Madrid, 1996.

RUEDA SOLER, N.: La Compañía comercial «Gardoqui e Hijos». 1760-1800, Servicio Central de Publicaciones del Gobierno Vasco, Vitoria, 1992.

SÁNCHEZ, A.: «La era de la manufactura algodonera en Barcelona, 1736-1839» en Estudios de Historia Social, (Madrid) 48-49 (1989) pp. 65-113.

SuARez CoRTiNA, M. (ed)): «Cantabria moderna en la historiografía». Historia de Cantabria. Un siglo de Historiografía y Bibliografía (1900-1994), Santander, 1995, tomo II, pp. $15-125$.

SOBRÓN IRURETAGOYENA, M.M: El transporte marítimo en el ámbito del desarrollo comercial. Santander, 1700-1800, Santander, 1992.

--------: «Tráfico colonial y flota mercante en el puerto de Santander durante el setecientos» en III Jornadas de Estudios portuarios y marítimos, Menorca, 1998.

ThOMPSON, J.: Els origens de la industrialització a Catalunya: el cotó a Barcelona, 17281832.- Península, Barcelona, 1994.

ZABALA, A: El comercio y tráfico marítimo del norte de España en el Siglo XVIII. La función comercial del País Vasco, Haranburu editor, San Sebastián, 1983.

: «La distribución de la actividad comercial en el Cantábrico en torno a los decretos de Libre Comercio» en Mercado y desarrollo económico en la España Contemporánea, Edit. S.XXI, Madrid, 1986, pp. 41-67

: Mundo urbano y actividad mercantil. Bilbao 1700-1810, Bilbao Bizkaia Kutxa, Bilbao, 1994

Hispania, LXIV/2, núm. 217 (2004) 601-636 
ANEXO I

CONVENTOS Y MONASTERIOS DESTINATARIOS

\begin{tabular}{|c|c|c|c|}
\hline LOCALIDAD & INSTITUCIÓN & LOCALIDAD & INSTITUCIÓN \\
\hline \multirow[t]{8}{*}{ MADRID } & Dominicos de Santo Tomás & BURGOS & Huelgas \\
\hline & Oratorio de San Felipe Neri & OÑA & Monaterio \\
\hline & Mercedarios de Góngora & MEDINA & Jerónimos \\
\hline & Mercedarios de Santa Bárbara & & Carmelitas Calzados \\
\hline & Franciscanos & & Franciscanos \\
\hline & Agonizantes & & Monjas Fajardas \\
\hline & Jerónimas de la Concepción & & Dominicos \\
\hline & Religiosas de Santa Rosalía & & Trinitarios \\
\hline EL PAULAR & Cartuja & & \\
\hline COLMENAR Viejo & Franciscanos & ESPINOSA & Bernardos \\
\hline OCAÑA & Franciscanos Recoletos & CALERUEGA & Dominicos \\
\hline FUENCARRAL & Escolapios & LERMA & Dominicas \\
\hline \multirow[t]{3}{*}{ ALCALÁ } & Trinitarios & VILLAFRUELA & Trinitarios Calzados \\
\hline & Agonizantes & Cuellar & Monjes Basilios \\
\hline & Calzados & Ávila & Franciscanos de San Antonio \\
\hline TALAVERA & Agonizantes & VALLADOLID & Vitorios \\
\hline CASARrubios & Bernardos & & Agustinos de San Gabriel \\
\hline POTES & Dominicos & & Agustinos Calzados \\
\hline Montes Claros & Dominicos & & Clérigos Menores \\
\hline LIÉBANA & Benitos de Santo Toribio & & San Diego \\
\hline CELORIO & Benitos & & Mercedarios Calzados \\
\hline BÁRCENA & Basilios & LA ESPINA & Bernardos \\
\hline REINOSA & Franciscanos & VILLALÓN & Vitorios \\
\hline \multirow[t]{2}{*}{ PALENCIA } & Convento de San Francisco & & Recoletos \\
\hline & Convento de San Buenaventura & & Franciscanos \\
\hline \multirow[t]{3}{*}{ Cervera } & Franciscanos Corpus Christi & MAYORGA & Franciscanos \\
\hline & Colegio de Jesús & & Agustinos \\
\hline & Jerónimos & MAZOTE & Dominicos \\
\hline HERRERA & Franciscanos de San Bernardino & NAVA & Agustinos \\
\hline \multirow[t]{2}{*}{ AGUILAR } & Franciscanos de Santa Clara & BENAVENTE & Religiosas Sancti Spiritus \\
\hline & Premostratenses & & Dominicos \\
\hline $\begin{array}{l}\text { S. ANDRÉS DEL } \\
\text { ARROYO }\end{array}$ & Bernardas & TORO & Franciscanos \\
\hline AMPUDIA & Franciscanos & VILLALPANDO & Dominicos \\
\hline CARRIÓN & Dominicos & $\cdot$ & Religiosas de Santa Clara \\
\hline \multirow[t]{2}{*}{ DUEÑAS } & Benitos & & Convento de San Isidro \\
\hline & Agustinos & VALPARAISO & Bernardos \\
\hline VILLASARRACINO & Benitos & SALAMANCA & Franciscanos \\
\hline \multirow[t]{3}{*}{ VILLALDABÍN } & Franciscanos & PEÑARANDA & Franciscanos \\
\hline & & LA ALBERCA & Frailes de San Miguel \\
\hline & & ESPEJA & Jerónimos \\
\hline
\end{tabular}

Fuente: Documentación indicada en nota 4

Hispania, LXIV/2, núm. 217 (2004) 601-636 